\title{
Application of Carbon Nanotube-Based Materials as Interlayers in High-Performance Lithium-Sulfur Batteries: A Review
}

\author{
Huijie Wei ${ }^{1}$, Yong Liu' ${ }^{1,2 *}$, Xiaoliang Zhai ${ }^{1}$, Fei Wang ${ }^{1}$, Xinyuan Ren ${ }^{3}$, Feng Tao', \\ Tengfei $\mathrm{Li}^{1}$, Guangxin Wang ${ }^{1}$ and Fengzhang Ren ${ }^{1 *}$ \\ ${ }^{1}$ Provincial and Ministerial Co-construction of Collaborative Innovation Center for Non-ferrous Metal New Materials \\ and Advanced Processing Technology, Henan Key Laboratory of Non-Ferrous Materials Science and Processing \\ Technology, School of Materials Science and Engineering, Henan University of Science and Technology, Luoyang, China, \\ ${ }^{2}$ National Joint Engineering Research Center for Abrasion Control and Molding of Metal Materials, Henan Key Laboratory \\ of High-Temperature Structural and Functional Materials, Henan University of Science and Technology, Luoyang, China, \\ ${ }^{3}$ School of Art and Design, Henan University of Science and Technology, Luoyang, China
}

OPEN ACCESS

Edited by:

Kai Zhu,

Harbin Engineering University, China

Reviewed by:

Yan-Bing He,

Tsinghua University, China

Xunhui Xiong,

South China University of Technology,

China

Hongshuai Hou,

Central South University, China

*Correspondence:

Yong Liu

liuyong209@haust.edu.cn

Fengzhang Ren

renfz@haust.edu.cn

Specialty section:

This article was submitted to Electrochemical Energy Conversion

and Storage,

a section of the journal

Frontiers in Energy Research

Received: 21 July 2020

Accepted: 14 August 2020

Published: 04 September 2020

Citation:

Wei H, Liu Y, Zhai X, Wang F, Ren $X$, Tao F, Li T, Wang G and Ren F

(2020) Application of Carbon

Nanotube-Based Materials as Interlayers in High-Performance

Lithium-Sulfur Batteries: A Review.

Front. Energy Res. 8:585795.

doi: 10.3389/fenrg.2020.585795
With the ever-increasing demands of electrochemical energy storage, lithium-sulfur ( $\mathrm{Li}-$ S) batteries have drawn more attention because of their superior theoretical energy density and high specific capacity. However, practical applications of Li-S batteries suffer from problems such as low conductivity of sulfur and discharged products, severe polysulfide shuttling effect, and large volume change of sulfur during cycling, resulting in sluggish rate performance, and unsatisfactory cycle life. Various nanostructured carbon materials have been served as barrier layers to overcome these problems. In particular, carbon nanotubes (CNTs) with unique 1D nanostructure, have been introduced to Li-S batteries as the intermediate layers because of its superior flexibility, excellent electrical conductivity, and good chemical stability. Moreover, CNTs and CNTs-based barrier layers could also curb lithium polysulfides shuttling. In the minireview, we summarize recent works of CNTs-based materials as modifying interlayers for Li-S batteries. In addition, the strategies to enhance electrochemical performances of the batteries are summarized and discussed. Finally, the challenges and prospects for future research of CNTs-based materials as interlayer are proposed. We hope this review will be useful for designing and fabricating high-performance Li-S batteries and boost their practical applications.

Keywords: lithium-sulfur batteries, carbon nanotubes, CNTs-based materials, interlayer, lithium polysulfides

\section{INTRODUCTION}

Nowadays, electric energy storage technology and equipment are gradually becoming a critical issue with the development of society (Wang F. et al., 2018; Wang R. et al., 2020; Liu et al., 2019a,b; Wu et al., 2019a; Zhao X. et al., 2019; Zhao et al., 2020; Li et al., 2020f; Ma et al., 2020b; Pan K. et al., 2020). In recent years, various electrochemical energy storage systems have been extensively studied (Ma et al., 2013, 2017, 2019; Luo et al., 2017; Chen H. et al., 2018; Guo et al., 2019, 2020; Liu et al., 2019c, 2020; Song C. et al., 2020; Wang F. et al., 2020; Yu et al., 2020; Zou P. et al., 2020). Among them, Li-S batteries have become one of the most promising candidates for next-generation electrochemical energy storage owing to their high theoretical specific capacity $\left(1675 \mathrm{mAh} \mathrm{g}^{-1}\right)$ and superior theoretical specific 
energy density (2600 Wh $\mathrm{Kg}^{-1}$ ), together with non-toxicity, low cost and environmental friendliness of sulfur (Yu et al., 2018; Gao et al., 2020).

However, there are some challenges for $\mathrm{Li}-\mathrm{S}$ batteries to overcome, including the electrical insulating characteristic of sulfur and the discharge product $\left(\mathrm{Li}_{2} \mathrm{~S}_{2} / \mathrm{Li}_{2} \mathrm{~S}\right)$, the large volumetric change of sulfur during the charge/discharge process (approximately 80\%), as well as the notorious shuttle effect caused by dissolved lithium polysulfides (LiPSs) (Huang et al., 2015; Cao et al., 2019; Chen Y.T. et al., 2019).

To address these problems, researchers have made considerable effort with regard to cathode and separator modification (Wang X. et al., 2019; Wei et al., 2019; Li et al., 2020a), optimization of electrolytes (Ding et al., 2016), and lithium metal anode protection and stabilization (Paolella et al., 2019; Pei et al., 2019). Among them, the interlayers could selectively control the shuttle effect of polysulfides, while not disturbing the $\mathrm{Li}^{+}$transfer. As a superior type of carbon material, carbon nanotubes (CNTs) have been intensively investigated as intermediate layers due to their excellent mechanical durability and high electrical conductivity as well as stable chemical properties. Together with other materials, CNTs-based interlayers are receiving considerable attentions for Li-S batteries in recent years (Wang et al., 2017; Jiang et al., 2018; Li et al., 2018; Son et al., 2019). For example, Yao M. et al. (2018) reported the multifunctional layer consisting of $\mathrm{MnO}_{2}$ and multi-walled CNTs modified polypropylene (PP) separator could tightly attract polysulfides and promote the transfer of electrons and ions, which could enhance the electrochemical performance of Li-S batteries. Li et al. (2018) designed and constructed a $\mathrm{MoS}_{2} / \mathrm{CNTs}$ interlayer to insert between separator and cathode, exhibited an optimized cycle performance and excellent rate capability. Some reviews also discussed recent developments on the interlayer materials for $\mathrm{Li}-\mathrm{S}$ batteries. For instance, Chen et al. reviewed on interlayer design of Li-S batteries by coating and inserting different types of carbon-based materials (Chen L. et al., 2020). Furthermore, Jiao et al. reviewed recent articles regarding to the interlayers for $\mathrm{Li}-\mathrm{S}$ batteries including carbon-based interlayers (Jiao et al., 2019); Pang and co-workers reviewed on recent research work on CNT-based materials for Li-S batteries (Zheng et al., 2019). However, there is still a lack of review to exclusively cover the state-of-the-art developments of CNTs-based interlayer materials for $\mathrm{Li}-\mathrm{S}$ batteries.

Herein, we provide an overview on carbon nanotubesbased materials as inter-layers of $\mathrm{Li}-\mathrm{S}$ batteries. Their nano/microstructure and electrochemical performances are summarized. In addition, some reasonable suggestion on their design and development are proposed to facilitate breakthroughs. We hope this review could attract more attentions to CNTsbased interlayer materials for $\mathrm{Li}-\mathrm{S}$ batteries and boost their practical applications.

\section{MWCNTs}

CNTs can be regarded as the curled graphene sheets, and they could be classified into two catagories, including multi-walled
CNTs (MWCNTs) and single-walled CNTs (SWCNTs) (Kumar S. et al., 2018; Ali et al., 2019). MWCNTs could be seen as the collection of multiple curled graphene sheets. Compared to SWCNTs, they are cheaper and easier to fabricate. Moreover, they remains the merits of high conductivity, low thermal expansion coefficient and stable structure (Zheng et al., 2019). For interlayers for Li-S batteries, MWCNTs are used mainly in two ways, (1) as the coating layer on separator (Cheng et al., 2016; Wang J. et al., 2018); (2) as the self-supporting film (Kim H.M. et al., 2016; Wang X. et al., 2020). The electrochemical performances of Li-S batteries with MWCNTs-based interlayers are summarized in Table 1.

\section{Separator-Based Interlayer}

As an essential part of $\mathrm{Li}-\mathrm{S}$ batteries, separators could separate the cathode and anode and prevent the internal short circuit. However, the pore size $(\sim 100 \mathrm{~nm})$ of commercial separators is much larger than the average size of long-chained polysulfides, which may cause the soluble polysulfides to easily migrate to the anodes, leading to notorious shuttle effect ( $\mathrm{Li}$ et al., 2020d). To prevent the shuttling of dissolved polysulfides, various MWCNTs-based materials have been developed to modify separators to provide physical entrapment and chemical adsorption for LiPSs, enhancing the electrochemical performances of Li-S batteries (Chang et al., 2015; Tan et al., 2018; Li et al., 2019e; Xiang et al., 2019).

\section{Pure MWCNTs}

As the most common CNT materials, MWCNTs have been intensively applied as interlayer coated on separator for $\mathrm{Li}-\mathrm{S}$ batteries. For example, Chung and Manthiram (2014) developed a MWCNT-coated separator as a barrier to anchor dissolved LiPSs, as shown in Figure 1A. The MWCNTs layer not only act as an upper current collector for rapidly electron transport and high sulfur utilization but also serve as a filter to trap and adsorb LiPSs. Meanwhile, the porous network of MWCNTs layer is conducive to electrolyte infiltration and electron/ion diffusion. Hence, the cell with MWCNTs-coated separator exhibited a superior long-term cycling performance. After 150 cycles, the cell with MWCNT layer delivered a specific capacity of 881 ,

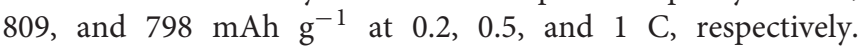
After that, researchers have paid more attention on carbon nanotubes modified separator to improve the performance of Li-S batteries. For instance, Ponraj et al. (2017) synthesized a hydroxyl-functionalized carbon nanotube $(\mathrm{CNTOH})$ coated on the separator, which could address the poor electronic conductivity of active materials and mitigate the diffusion and migration of LiPSs in Li-S batteries owing to the good conductivity and hydroxyl groups of $\mathrm{CNTOH}$.

\section{MWCNTs-Based Composites}

Nano-composite materials normally have a better performance than single-component materials due to the synergistic effect of different components, which have attracted extensive attention from researchers in recent years (Luo Y. et al., 2018; Guan B. et al., 2019; Kim et al., 2020; Ma et al., 2020a; Wang W. et al., 2020). Many types of MWCNTs-based composites, 
TABLE 1 | Electrochemical performance of Li-S batteries employing CNT-based materials as interlayer.

\begin{tabular}{|c|c|c|c|c|c|c|c|}
\hline Materials & $\begin{array}{l}\text { Mass load } \\
\left(\mathrm{mg} \mathrm{cm}^{-2}\right)\end{array}$ & $\begin{array}{c}\text { Sulfur contents } \\
\text { (wt\%)/loading (mg } \\
\text { cm }^{-2} \text { ) }\end{array}$ & $\begin{array}{l}\text { Current } \\
\text { density }\end{array}$ & $\begin{array}{c}\text { Cycle } \\
\text { number }\end{array}$ & $\begin{array}{c}\text { Initial } \\
\text { capacity } \\
\left(\mathrm{mAh} \mathrm{g}^{-1}\right)\end{array}$ & $\begin{array}{l}\text { Post-cycle } \\
\text { capacity } \\
\left(\mathrm{mAh} \mathrm{g}^{-1}\right)\end{array}$ & References \\
\hline MWCNT & 0.17 & $70 / 2$ & $\mathrm{C} / 5$ & 150 & 1324 & 881 & Chung and Manthiram, 2014 \\
\hline DWCNT & 0.00477 & $60 / 1.5-2$ & $0.1 \mathrm{C}$ & 100 & 598 & 508 & Sun et al., 2020 \\
\hline O-MWCNT & 0.4 & $90 / 5$ & $0.1 \mathrm{~A} \mathrm{~g}^{-1}$ & 50 & 1105 & 925 & Cheng et al., 2016 \\
\hline CNT & - & $-1-$ & $1 \mathrm{C}$ & 500 & 684 & 361 & Liu et al., 2017 \\
\hline aCNT & $\sim 0.15$ & $67 / 1.5$ & $0.5 \mathrm{C}$ & 500 & 1306 & 621 & Huang et al., 2018 \\
\hline CNTOH & 1.34 & $70 / 3$ & $0.5 \mathrm{C}$ & 400 & 1056 & $\sim 591$ & Ponraj et al., 2017 \\
\hline OCNT & - & $-/ 1.5$ & $0.5 \mathrm{C}$ & 400 & 1034.9 & $\sim 732$ & Kim et al., 2018 \\
\hline CNT & $r 5$ & $80 / 1.3$ & $1 \mathrm{C}$ & 200 & 968 & $\sim 670$ & Manoj et al., 2018a \\
\hline SCL & 0.25 & $70 / 1.35-1.55$ & $1 \mathrm{C}$ & 400 & 1073 & 700.4 & Geng et al., 2020 \\
\hline $\mathrm{MoS}_{2} @ \mathrm{CNT}$ & - & $77.5 /-$ & $1 \mathrm{C}$ & 500 & $\sim 690$ & $\sim 670$ & Jeong et al., 2017 \\
\hline $\mathrm{Sb}_{2} \mathrm{~S}_{3} / \mathrm{CNT}$ & 0.4 & $65 / 1.0$ & $1 \mathrm{C}$ & 1000 & $\sim 720$ & 373 & Yao S. et al., 2018 \\
\hline $\mathrm{SnS}_{2} / \mathrm{CNT}$ & 0.4 & $78 / 1.4$ & $2 \mathrm{C}$ & 800 & $\sim 782$ & 555 & Jiang et al., 2019 \\
\hline NSCNTs/MoS2 & 0.5 & $88.3 / 2.2$ & $1 \mathrm{C}$ & 1000 & 1024 & 814 & Xiang et al., 2019 \\
\hline SWCNT & 0.13 & $80 / 3.0$ & $0.2 \mathrm{C}$ & 100 & 953 & 713 & Chang et al., 2016 \\
\hline PANINF/MWCNT & 0.01 & $60 / 1.4$ & $0.2 \mathrm{C}$ & 100 & 1020 & 709 & Chang et al., 2015 \\
\hline MCNT@PEG & 0.26 & $60 / 1.6$ & $0.5 \mathrm{C}$ & 200 & 1283 & 727 & Wang et al., 2015 \\
\hline MWCNT/PEG & 0.12 & $78 / 6.5$ & $0.2 \mathrm{C}$ & 300 & 1206 & 630 & Luo et al., 2016 \\
\hline PEI/MWCNT) & - & $75 / 1.1$ & $2 \mathrm{C}$ & 300 & 819 & $\sim 590$ & Lee Y.-H. et al., 2018 \\
\hline MWCNT/NCQD & 0.15 & $60 / 1.3-1.5$ & $0.5 \mathrm{C}$ & 1000 & 1330.8 & 507.9 & Pang et al., 2018 \\
\hline PC/MWCNT & 0.51 & $70 / 1.6-1.7$ & $0.5 \mathrm{C}$ & 200 & 911 & 659 & Tan et al., 2018 \\
\hline $\mathrm{G} / \mathrm{CNT}$ & 0.17 & $75 / 1.7-2$ & $0.5 \mathrm{C}$ & 100 & $\sim 913.5$ & 813 & Gao et al., 2019b \\
\hline $\mathrm{GO} / \mathrm{CNT}$ & - & $60 / 1.1$ & $0.2 \mathrm{C}$ & 50 & 1591.56 & 1003 & Lee et al., 2019 \\
\hline EB & 0.2 & $70 / 1.8$ & $0.2 \mathrm{C}$ & 100 & $950\left(25^{\text {th }}\right)$ & 980 & Lu et al., 2019 \\
\hline Co/NCNS/CNT & 0.2 & $80 / 2$ & $2 \mathrm{C}$ & 1000 & 972.4 & $\sim 486$ & Song C.L. et al., 2020 \\
\hline $\mathrm{CNT} / \mathrm{Al}_{2} \mathrm{O}_{3}$ & - & $60 / 1$ & $0.2 \mathrm{C}$ & 100 & 1282 & 807.8 & Xu Q. et al., 2015 \\
\hline $\mathrm{Al}_{2} \mathrm{O}_{3} / \mathrm{CNT}$ & - & $70 / 1.0-1.2$ & $0.2 \mathrm{C}$ & 100 & 1096 & 760.4 & Chen X. et al., 2020 \\
\hline $\mathrm{Fe}_{3} \mathrm{O}_{4} @ \mathrm{C} / \mathrm{CNTO}$ & 0.288 & $65 / 1.5$ & $2 \mathrm{C}$ & 1000 & $\sim 833$ & 335 & Du et al., 2020 \\
\hline CNTs@FeOOH & - & $55 / 0.8$ & $3.2 \mathrm{~A} \mathrm{~g}^{-1}$ & 350 & 1121.9 & 556 & Li et al., 2020e \\
\hline $\mathrm{MgBO}_{2}(\mathrm{OH}) / \mathrm{CNT}$ & 0.3 & $70 / 1.1$ & $0.5 \mathrm{C}$ & 200 & 924 & 785 & Kong L. et al., 2017 \\
\hline $\mathrm{CNT@TiO} 2$ & 0.7 & $66.4 / 1.7$ & $0.1 \mathrm{C}$ & 200 & 1351 & 803 & Yang et al., 2017 \\
\hline $\mathrm{TiO}_{2} / \mathrm{CNTS}$ & 0.3 & $70 / 1.5$ & $1 \mathrm{C}$ & 250 & 1036.9 & 763 & Guan Y. et al., 2019 \\
\hline MWCNTs @TiO 2 & - & $60 / 0.8-1.0$ & $838 \mathrm{~mA} \mathrm{~g}^{-1}$ & 600 & 1083 & 610 & Ding et al., 2018 \\
\hline Ni-MOF/MWCNTS & 0.36 & $60 / 1.58$ & $0.5 \mathrm{C}$ & 300 & 1358 & 1183 & Lee D.H. et al., 2018 \\
\hline $\mathrm{CNT} / \mathrm{ZrO}_{2}$ & - & $50 / 1.5$ & $0.1 \mathrm{C}$ & 120 & 1207 & 685 & Liu et al., 2018 \\
\hline $\mathrm{MoO}_{3} @ \mathrm{CNT}$ & 0.577 & $60 / 1$ & $0.3 \mathrm{C}$ & 200 & 1251 & 755 & Luo L. et al., 2018 \\
\hline $\mathrm{CNT} / \mathrm{MoP}_{2}$ & 0.34 & $50 / 1.2$ & $0.2 \mathrm{C}$ & 100 & 1223 & 905 & Luo Y. et al., 2018 \\
\hline
\end{tabular}


TABLE 1 | Continued

\begin{tabular}{|c|c|c|c|c|c|c|c|}
\hline Materials & $\begin{array}{l}\text { Mass load } \\
\left(\mathrm{mg} \mathrm{cm} \mathrm{cm}^{-2}\right)\end{array}$ & $\begin{array}{c}\text { Sulfur contents } \\
\text { (wt \%)/loading (mg } \\
\mathrm{cm}^{-2} \text { ) }\end{array}$ & $\begin{array}{l}\text { Current } \\
\text { density }\end{array}$ & $\begin{array}{c}\text { Cycle } \\
\text { number }\end{array}$ & 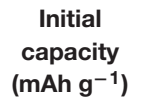 & 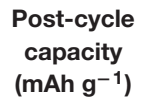 & References \\
\hline CNT@ZIF & 0.9 & $70.2 / 1.2$ & $0.2 \mathrm{C}$ & 100 & 1588.4 & 870.3 & Wu et al., 2018 \\
\hline COF-CNT & - & $80 / 2$ & $1 \mathrm{Ag}^{-1}$ & 500 & 1068 & 621 & Wang J. et al., 2020 \\
\hline $\mathrm{MoS}_{2} / \mathrm{CNT}$ & 0.25 & $50 / 1.4$ & $0.5 \mathrm{C}$ & 500 & 1237 & 648 & Yan et al., 2018 \\
\hline MWCNTs/ $\mathrm{MnO}_{2}$ & $0.20-0.48$ & $60 / 1,4$ & $1 \mathrm{C}$ & 500 & $\sim 880$ & $\sim 610$ & Yao M. et al., 2018 \\
\hline $\mathrm{TiO}_{2} / \mathrm{CNT}$ & - & $73 / 2$ & $1 \mathrm{C}$ & 200 & 936 & 557 & Chen A. et al., 2019 \\
\hline $\mathrm{TiO}_{2} / \mathrm{CNT}$ & - & $70 / 0.86$ & $0.2 \mathrm{C}$ & 100 & 1247 & 627 & Chen P. et al., 2020 \\
\hline $\mathrm{TiS}_{2} / \mathrm{CNT}$ & 0.6 & $69.7 / 2$ & $0.5 \mathrm{C}$ & 100 & 1012 & 848 & Pan S. et al., 2020 \\
\hline MWCNTs/ $\mathrm{CeO}_{2}$ & 0.15 & $60 / 1.8-2.0$ & $0.2 \mathrm{C}$ & 300 & 898.3 & 520.7 & Zhu et al., 2020 \\
\hline $\mathrm{Sc}_{2} \mathrm{O}_{3} @ \mathrm{CNT}$ & 0.17 & $65 / 1.5$ & $1 \mathrm{C}$ & 500 & 1037 & 788 & Xu et al., 2020 \\
\hline $\mathrm{Co}_{2} \mathrm{~B} @ \mathrm{CNT}$ & - & $72.45 / 3.6$ & $0.2 \mathrm{C}$ & 200 & 1430 & 1283 & Guan B. et al., 2019 \\
\hline $\mathrm{PCCNT} / \mathrm{Ni}_{2} \mathrm{P}$ & 0.8 & $78.8 / 1.1-1.2$ & $1 \mathrm{C}$ & 500 & 1067 & 654.2 & Guang et al., 2019 \\
\hline Ce-MOF/CNT & 0.4 & $80 / 2.5$ & $1 \mathrm{C}$ & 800 & 1021.8 & 838.8 & Hong et al., 2019 \\
\hline CNTs/MXene & 0.16 & $70 / 0.8-2.5$ & $1 \mathrm{C}$ & 600 & 987 & 614 & Li et al., 2019a \\
\hline $\mathrm{Ti}_{3} \mathrm{C}_{2} \mathrm{~T}_{x} / \mathrm{CNTs}$ & 0.016 & $70 / 1.2$ & $1 \mathrm{C}$ & 200 & 760 & 640 & Li et al., 2020b \\
\hline TiO/MWCNT & 0.7 & $60 / 1.4-1.6$ & $0.5 \mathrm{C}$ & 200 & 1527.2 & 1033.8 & Li et al., 2019e \\
\hline $\mathrm{Ta}_{2} \mathrm{O}_{5} / \mathrm{CNT}-\mathrm{O}$ & - & $80 / 1.5$ & $0.2 \mathrm{C}$ & 100 & 1230.7 & 932.6 & Li et al., $2019 f$ \\
\hline $\mathrm{CNTs} / \mathrm{Fe}_{3} \mathrm{O}_{4}$ & 0.38 & $72 / 1.4$ & $1 \mathrm{C}$ & 1000 & $\sim 750$ & 651 & Sun et al., 2019b \\
\hline $\mathrm{MnO}_{2} / \mathrm{CNT}$ & 0.35 & $70 / 0.8$ & $1 \mathrm{C}$ & 500 & 843.7 & $\sim 574$ & Wang Y. et al., 2019 \\
\hline Co/NCNS/CNT & 0.2 & $80 / 2$ & $2 \mathrm{C}$ & 1000 & 972.4 & 434 & Song C.L. et al., 2020 \\
\hline $\mathrm{B}-\mathrm{CNT}$ & 0.06 & $70 / 2.4-2.5$ & $0.2 \mathrm{C}$ & 500 & $\sim 675$ & 509 & Chung et al., 2016 \\
\hline Gr-CNT-Ni & 0.2 & $64 / 7.68$ & $0.2 \mathrm{C}$ & 100 & 849 & 549 & Kumar G.G. et al., 2018 \\
\hline $\mathrm{W}-\mathrm{V}_{2} \mathrm{O}_{5}-\mathrm{G} / \mathrm{CNT}$ & 0.11 & $75 / 1.7-2$ & $0.5 \mathrm{C}$ & 200 & $\sim 910$ & 815 & Gao et al., 2019a \\
\hline $\mathrm{HfO}_{2} / \mathrm{CNT}$ & 0.087 & $75 / 1.80-2.22$ & $1 \mathrm{C}$ & 500 & $\sim 1060$ & 721 & Kong et al., 2018 \\
\hline ACNTS & - & $90 / 2.2-2.5$ & $0.5 \mathrm{C}$ & 1400 & 897 & 713 & Chen M. et al., 2018 \\
\hline \multicolumn{8}{|c|}{ Freestanding interlayer } \\
\hline MWCNT/RGO & 1 & $70 / 1.5-1.8$ & $1 \mathrm{C}$ & 350 & 908 & 611 & Sun et al., 2018 \\
\hline MWCNT & $0.83-1.1$ & $70 /-$ & $0.2 \mathrm{C}$ & 50 & $\sim 1420$ & 962 & Su and Manthiram, 2012 \\
\hline GF/CNT & 0.54 & $70 / 1.6$ & $0.2 \mathrm{C}$ & 230 & 1111.7 & 802.8 & Lee and Kim, 2015 \\
\hline DF/PCW & - & $56 / 1.8-2.7$ & $1 \mathrm{C}$ & 100 & 1113 & 1040.6 & Hwang et al., 2016 \\
\hline MWCNT & 1.95 & $80 / 3$ & $0.5 \mathrm{C}$ & 100 & 851 & $\sim 664$ & Kim H.M. et al., 2016 \\
\hline CNT & $\sim 0.256$ & $60 /-$ & $0.5 \mathrm{C}$ & 500 & 872 & 460 & Sun et al., 2016 \\
\hline CNTs & 1.0 & $70 / 0.974$ & $0.25 \mathrm{C}$ & 100 & 1658 & 556 & Li et al., 2017 \\
\hline CNT & 0.45 & $45 / 4$ & $0.5 \mathrm{C}$ & 80 & $\sim 1160$ & 981 & Xie et al., 2017 \\
\hline CNTs & 1 & $-/ 3$ & $1 \mathrm{C}$ & 200 & 943 & 802 & Peng et al., 2019 \\
\hline SMAP & - & $70 /-$ & $1 \mathrm{C}$ & 200 & 849 & 806 & Rui et al., 2019 \\
\hline $\mathrm{C}-\mathrm{C}-\mathrm{N}-\mathrm{Co}$ & 0.45 & $70 / 1$ & $0.5 \mathrm{C}$ & 100 & $\sim 1060$ & 787 & Li et al., $2020 \mathrm{~g}$ \\
\hline UPHC & - & $60 / 1.5-2.0$ & $0.5 \mathrm{C}$ & 300 & 704.5 & 608.8 & Wang X. et al., 2020 \\
\hline SWCNT & - & $70 /-$ & $0.1 \mathrm{C}$ & 50 & 1674 & 1052 & Kaiser et al., 2015 \\
\hline PAA-SWNT & 0.82 & $65 / 2.7$ & $1 \mathrm{C}$ & 200 & $\sim 770$ & 573 & Kim J.H. et al., 2016 \\
\hline SWCNT & 1 & $50 / 1.0-1.2$ & $0.8 \mathrm{~A} \mathrm{~g}^{-1}$ & 1500 & 1034 & 408 & Jin et al., 2018 \\
\hline SWCNT/rGO & 0.1 & $60 / 1$ & $1 \mathrm{Ag}^{-1}$ & 80 & 773 & $\sim 605$ & Hao J. et al., 2019 \\
\hline PEDOT:PSS-CNT & 0.7 & $60 / 2$ & $0.5 \mathrm{C}$ & 50 & 793 & 690 & Wang et al., 2017 \\
\hline $\mathrm{GO} / \mathrm{CNT}$ & 1.1 & $70 / 1$ & $0.2 \mathrm{C}$ & 300 & 1370 & 671 & Huang et al., 2016 \\
\hline CNTs/RGO & 0.34 & $70 / 2$ & $4 \mathrm{C}$ & 600 & $\sim 765$ & 597 & Liu et al., 2016 \\
\hline MWCNTs/RGO & 1 & $70 / 1.5-1.8$ & $0.2 \mathrm{C}$ & 100 & 1224 & 854 & Sun et al., 2018 \\
\hline CNTF & $5-7.6$ & $80 / 1.3$ & $1 \mathrm{C}$ & 200 & 542 & 384 & Manoj et al., 2019 \\
\hline $\mathrm{G} / \mathrm{CNT}$ & 0.2 & $50 / 2.46$ & $2 \mathrm{C}$ & 500 & $\sim 460$ & 445 & Shi et al., 2019 \\
\hline $\mathrm{CNTP} / \mathrm{TiO}_{2}$ & - & $70 / 0.98$ & $0.5 \mathrm{C}$ & 250 & $\sim 1575$ & 575.8 & Xu G. et al., 2015 \\
\hline G/M@CNT & 0.104 & $60-80 / 1.11-1.37$ & $1 \mathrm{C}$ & 2500 & $\sim 1065$ & 293 & Kong W. et al., 2017 \\
\hline $\mathrm{MoS}_{2} / \mathrm{CNTP}$ & 0.04 & $70 / 3.4$ & $0.5 \mathrm{C}$ & 100 & 1233 & 850 & Li et al., 2018 \\
\hline CNF@VS $2 / C N T @ G N$ & 1.9 & $60 / 1$ & $1 \mathrm{C}$ & 1145 & 1138.4 & 605 & Wang L. et al., 2018 \\
\hline
\end{tabular}


TABLE 1 | Continued

\begin{tabular}{|c|c|c|c|c|c|c|c|}
\hline Materials & $\begin{array}{l}\text { Mass load } \\
\left(\mathrm{mg} \mathrm{cm} \mathrm{cm}^{-2}\right)\end{array}$ & $\begin{array}{c}\text { Sulfur contents } \\
\text { (wt\%)/loading (mg } \\
\mathrm{cm}^{-2} \text { ) }\end{array}$ & $\begin{array}{l}\text { Current } \\
\text { density }\end{array}$ & $\begin{array}{c}\text { Cycle } \\
\text { number }\end{array}$ & $\begin{array}{c}\text { Initial } \\
\text { capacity } \\
\left(\mathrm{mAh} \mathrm{g}^{-1}\right)\end{array}$ & $\begin{array}{l}\text { Post-cycle } \\
\text { capacity } \\
\left(\mathrm{mAh} \mathrm{g}^{-1}\right)\end{array}$ & References \\
\hline $\mathrm{Fe}_{3} \mathrm{C}-\mathrm{C}-\mathrm{CNTS}$ & - & $-/ 1.5$ & $0.2 \mathrm{C}$ & 100 & 1243 & 870.2 & Wang S. et al., 2020 \\
\hline $\mathrm{CeF}_{3} / \mathrm{CNTS}$ & $0.8-2$ & $90 / 1.2-1.4$ & $0.2 \mathrm{C}$ & 100 & 1015 & 951 & Zou K. et al., 2020 \\
\hline $\mathrm{Pd}_{3} \mathrm{Co} / \mathrm{MWCNTS}$ & - & $60 / 1$ & $2 \mathrm{C}$ & 300 & 953 & 752 & Cho et al., 2019 \\
\hline Pt@CNT & - & $60 / 0.7$ & $0.5 \mathrm{C}$ & 400 & 1120 & 660 & Ding et al., 2019 \\
\hline MWCNTS-OH & - & $70 / 2-2.3$ & $1 \mathrm{C}$ & 500 & 601 & 516 & Huang et al., 2019 \\
\hline MTO-CNT & 0.06 & $65 / 1.1-3$ & $0.5 \mathrm{C}$ & 500 & 931.7 & 634.6 & Li et al., 2019b \\
\hline $\mathrm{SiO}_{2} / \mathrm{AP}$ & - & $87 /-$ & $1 \mathrm{C}$ & 200 & $\sim 1087$ & 1039 & Li et al., 2019d \\
\hline ВTO/C & - & $60 / 0.94$ & $0.2 \mathrm{C}$ & 200 & $\sim 1201$ & 908 & Son et al., 2019 \\
\hline ZnO/CNT/RGO & 0.85 & $-/ 1.7$ & $0.2 \mathrm{C}$ & 150 & 1061 & 768 & Sun et al., 2019a \\
\hline
\end{tabular}

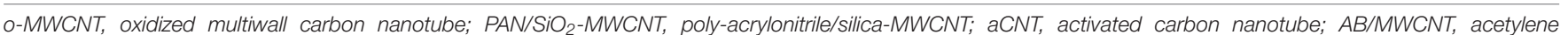
black/MWCNT; SCL, sandwich-structure composite carbon layer (a N-doped mesoporous carbon sandwiched between two carbon nanotube); NSCNTS/MoS,

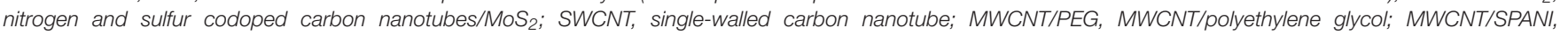

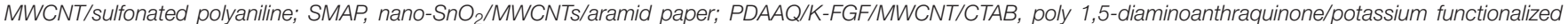

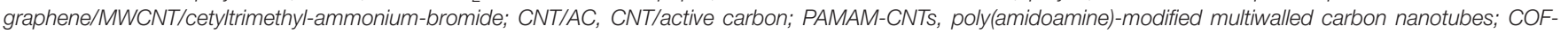

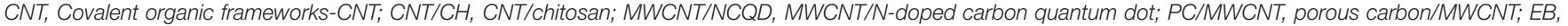

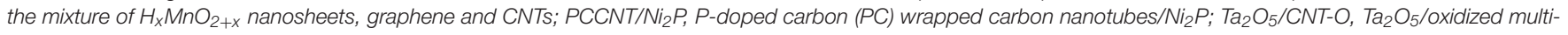

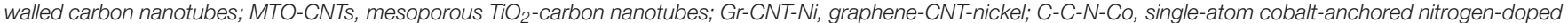

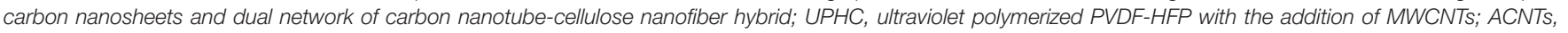

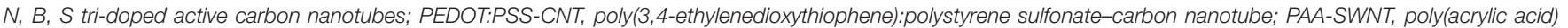

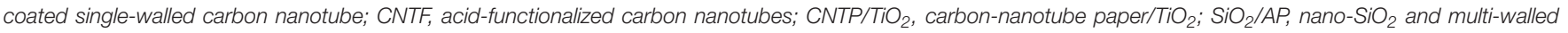

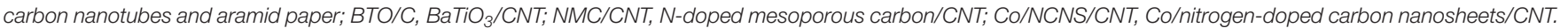
The symbol "-" in the table means that there is no relevant information in the reference.

such as MWCNTs/carbonaceous material composites, MWCNTs/polymer composites and MWCNTs/metal-based compound composites have been applied as interlayer coated on separator for Li-S batteries. For example, Pang et al. (2018) fabricated a MWCNT/N-doped carbon quantum dots (NCQDs) composites as coating layer onto the separator for $\mathrm{Li}-\mathrm{S}$ batteries (Figure 1B). The NCQDs with large surface area and rich oxygenated functional groups could be regarded as an efficient adsorbent for LiPSs, meanwhile, MWCNTs are beneficial to enhance the conductivity of composites. Therefore, the cell with MWCNT/NCQDs-coated separators displayed an excellent electrochemical performance, as well as an average self-discharge value of $\sim 11 \%$ after resting for $48 \mathrm{~h}$, which is lower than that with the pristine MWCNTs-modified separator (Figure 1B).

MWCNTs/Polymer composites have also been fabricated to trap LiPSs through physical obstructing and chemical bonding in Li-S batteries (Chang et al., 2015; Luo et al., 2016; Lee Y.H. et al., 2018). For Lee Y.-H. et al. (2018) instance, developed a spiderweb separator consisting of three functional nanomats with good mechanical properties and excellent electrical conductivity. In this sandwich-type separator, MWCNT-wrapped polyetherimide (PEI/MWCNT) nanomats were used as the top and bottom layer, and the PVIm[TFSI]/poly(vinylidene fluorideco-hexafluoropropylene) (PVDF-HFP) with a polyethylene (PE) nanomat was the middle layer (Figure 1C). When tested in $\mathrm{Li}-\mathrm{S}$ batteries, the cell with this composites separator exhibited higher discharge capacity and more stable cycling performance than that with pristine PE separator (Lee Y.-H. et al., 2018).

Metal-based compounds are mainly including metal oxides (Ding et al., 2018; Luo L. et al., 2018), metal sulfides (Jeong et al., 2017; Xiang et al., 2019), metal phosphides (Luo Y. et al., 2018), metal borides (Guan B. et al., 2019), metal hydroxides (Kong L. et al., 2017) and metal-organic frameworks (MOFs) (Lee D.H. et al., 2018; Wu et al., 2018), which could offer a polar chemical interaction with LiPSs and curb polysulfides shuttling in Li-S batteries. For instance, Hong et al. (2019) fabricated cerium-MOFs/MWCNTs composites as coating material on separators for Li-S batteries at a high sulfur loading of $6 \mathrm{mg}$ $\mathrm{cm}^{-2}$, the cell with the modified separators could deliver an initial specific capacity of $993.5 \mathrm{mAh}^{-1}$ at $0.1 \mathrm{C}$, and the specific capacity of $886.4 \mathrm{mAh} \mathrm{g}^{-1}$ was retained after 200 cycles (Figure 1D). The superior electrochemical performance is ascribed that $\mathrm{Ce}-\mathrm{MOF} / \mathrm{MWCNTs}$ can mitigate the transmission and diffusion of polysulfides and boost the efficient catalytic conversion of LiPSs, owing to their uniformly dispersed catalytic active sites and large specific surface area as well as good electronic conductivity. Yao S. et al. (2018) successfully exfoliated a $2 \mathrm{D}$ antimony sulfides $\left(\mathrm{Sb}_{2} \mathrm{~S}_{3}\right)$ sheets and combined them with MWCNTs $\left(\mathrm{Sb}_{2} \mathrm{~S}_{3} / \mathrm{MWCNTs}\right)$ to modify the Celgard PP separator (Figure 1E). With $\mathrm{Sb}_{2} \mathrm{~S}_{3} / \mathrm{MWCNT}$ modified separator, the Li$S$ cell exhibited a low average capacity decay rate $(\sim 0.049 \%$ per cycle after cycling 1000 cycles at $1 \mathrm{C}$ ), indicated that the $\mathrm{Sb}_{2} \mathrm{~S}_{3} / \mathrm{MWCNTs}$ has a strong interaction with polysulfides which was confirmed by the first-principle calculation.

\section{Free-Standing Interlayer}

In addition to coating MWCNTs-based materials onto the separator to curb the shuttling of lithium polysulfides, another alternative strategy is to insert a self-supporting interlayer between the cathode and separator (Wang et al., 2017; Sun et al., 2018). The self-supported interlayers are usually much thicker than the modified-separators interlayers, and they are supposed 


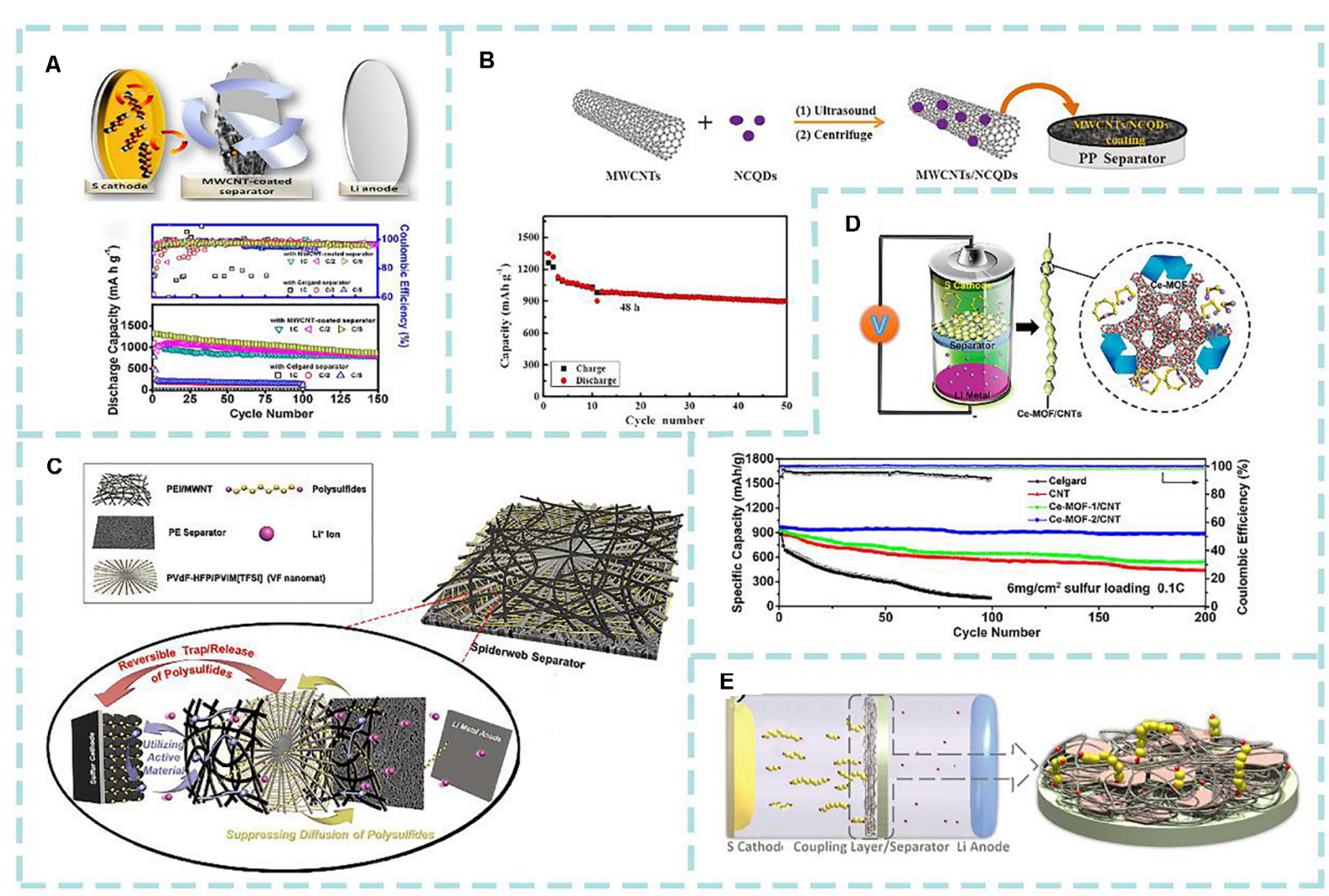

FIGURE 1 | (A) Mechanism of multi-walled carbon nanotubes (MWCNTs)-coated separator for Li-S batteries and the corresponding cycling performance; (B) Schematic diagram of MWCNTS/N-doped carbon quantum dots (MWCNTs/NCQDs)-coated separator preparation process and the cycle performance of the Li-S battery with MWCNTS/NCQDs-coated separator; (C) Schematic illustration of spiderweb separator and its application in Li-S batteries; (D) Scheme of Ce-MOFs/CNTs as coating materials in Li-S battery and the corresponding cyclic performance; (E) Schematic configuration of the Li-S cell with a Sb $2 \mathrm{~S}_{3} / \mathrm{CNTS}_{\mathrm{S}}$ coated membrane. (A) Reproduced with permission. Chung and Manthiram (2014) Copyright 2014, American Chemical Society. (B) Reproduced with permission. Pang et al. (2018) Copyright 2018, Wiley-VCH. (C) Reproduced with permission. Lee Y.-H. et al. (2018) Copyright 2018, Wiley-VCH. (D) Reproduced with permission. Hong et al. (2019) Copyright 2019, American Chemical Society. (E) Reproduced with permission. Yao S. et al. (2018) Copyright 2018, Wiley-VCH.

to have the characteristics of strong chemical and/or physical adsorption toward polysulfides, good container for polysulfides and good electronic conductor. Also, the interlayer should allow smooth Li-ion diffusion. Therefore, with the insertion of interlayers, the LiPSs could be blocked at the cathode side, and the $\mathrm{Li}^{+}$diffusion and electron tranfer could also be promoted (Huang et al., 2016).

\section{Pure MWCNTs}

Because of intrinsic interweaving properties of CNTs, it is easy to prepare freestanding $\mathrm{CNT}$ interlayers with good flexibility and high porosity. Manthiram (Su and Manthiram, 2012) firstly fabricated a freestanding MWCNTs membrane by ultrasonic dispersion of synthesized MWCNTs, followed by a facile vacuum filtration (Supplementary Figure S1A). With the insertion of this freestanding interlayer, interfacial resistance in cathode was greatly reduced, and the intermediate polysulfides was efficiently localized at cathode side. The enhanced cycling performance of Li-S battery with MWCNTs interlayers could be ascribed that MWCNTs can prevent the undesirable migration and diffusion of polysulfides (Su and Manthiram, 2012). After that, many other interlayers based on MWCNTs have been explored for LiS batteries (Lee and Kim, 2015; Sun et al., 2016). For instance, Kim H.M. et al. (2016) prepared a self-assembled MWCNTs membrane by mixing MWCNTs and electrolyte, followed by being applied to the top of sulfur electrode (Supplementary Figure S1B). The self-assembled MWCNTs membrane has more tightly interwoven structure and denser than bare MWCNTs interlayer. When tested in Li-S batteries, after 100 cycles at $0.5 \mathrm{C}$, the surface of the self-assembled MWCNTs interlayer only has tiny pores and more densely packed shape than that of bare MWCNTs interlayer. The enhanced electrochemical performance of the cell with self-assembled MWCNTs interlayer could be attributed to efficiently hinder polysulfide diffusion and enhance sulfur utilization through supplying polysulfide capturing sites (Kim H.M. et al., 2016).

\section{MWCNTs-Based Composites}

Owing to the abundance of functional groups, large specific surface area, and excellent electrical conductivity, graphene has attracted more interest in energy storage materials fields 
(Wu et al., 2019b; Ma et al., 2020c; Sui et al., 2020). In Li-S batteries, many researchers combined graphene with MWCNTs as barrier materials to inhibit polysulfides migration (Sun et al., 2018; Shi et al., 2019). For instance, Huang et al. synthesized a freestanding graphene oxide/MWCNTs (GO/MWCNTs) film through combining MWCNTs with GO sheets (Huang et al., 2016), which exhibited high electronic conductivity and strong ability to immobilize LiPSs in Li-S batteries, resulting in improved electrochemical performance. The cell with GO/MWCNTs depicted an outstanding initial specific capacity of $1370 \mathrm{mAh} \mathrm{g}^{-1}$ at 0.1 C. After 300 cycles at $0.2 \mathrm{C}$, it still maintained a discharge capacity of $671 \mathrm{mAh}^{-1}$, and the corresponding capacity decay rate was about $0.043 \%$ per cycle. More recently, Shi et al. (2019) reported a three-dimensional graphene/multi-walled carbon nanotube aerogels (G/MWCNTs) as self-supporting interlayer to improve the performance of $\mathrm{Li}-\mathrm{S}$ cells. As displayed in Supplementary Figure S1D, this 3D G/MWCNTs aerogels with a 3D interconnected porous network were fabricated by the rapid reduction of graphene oxide/MWCNTs aerogel via self-propagating combustion. Cross-linked MWCNTs with graphene can give the membrane good mechanical flexibility and abundant pores, so that it can prevent the damage of interlayer during battery assembly and has more active sites to anchor polysulfides by chemical interaction and physical confinement.

In addition to combining with graphene, some researchers also combined MWCNTs with polar materials such as metal oxides (Xu G. et al., 2015; Kong W. et al., 2017; Kong et al., 2018; Li et al., 2019b), metal sulfides ( $\mathrm{Li}$ et al., 2018; Wang L. et al., 2018), and metal catalyst (Cho et al., 2019; Ding et al., 2019), which could have produced strong chemical interactions with polysulfides. For instance, Wang L. et al. (2018) integrated a multicomponent sandwich structure interlayer as freestanding interlayer inserting between the sulfur cathode and separator, and the Li-S cell has been displayed outstanding electrochemical performance. In the structure, $\mathrm{CNF}$ is used as a scaffold to support $\mathrm{CNT}$ and vanadium disulfide compounds $\left(\mathrm{VS}_{2} / \mathrm{CNT}\right)$, and covered a graphene layer onto it in the end. As shown in Supplementary Figure S1C, the CNT containing $\mathrm{VS}_{2}$ had stronger adsorption ability toward polysulfides than pure $\mathrm{CNT}$, suggesting that the polar $\mathrm{V}-\mathrm{S}$ bonds in $\mathrm{VS}_{2}$ promote the adsorption toward polysulfide. With the introduction of $\mathrm{VS}_{2} / \mathrm{CNT}$, the interlayer exhibited excellent synergetic effects to trap LiPSs and suppress the self-discharge effect (Wang L. et al., 2018).

\section{SWCNTs}

SWCNTs can be regarded as an ideal scaffold to anchor polysulfides in $\mathrm{Li}-\mathrm{S}$ batteries due to their relatively uniform diameters and excellent mechanical and electrical properties, which could allow fast electron transfer (Zhao et al., 2012; Fang et al., 2017). Many efforts have been devoted to SWCNTs-based materials as interlayer for Li-S batteries (Kaiser et al., 2015;
Chang et al., 2016; Hao J. et al., 2019). For example, Kaiser et al. (2015) synthesized a refined and interwoven structured SWCNTs freestanding film as the barrier layer, and inserted it between sulfur cathode and separator, which could effectively restrain polysulfides, enhancing the electrochemical performance of $\mathrm{Li}-\mathrm{S}$ batteries.

Later, Kim J.H. et al. (2016) fabricated a polymer-coated single-wall carbon nanotube membrane (PAA-SWCNTs) as functional interlayer, which could efficiently restrain the diffusion of polysulfides via physical blocking of SWCNTs scaffold and hydrogen-bonding interaction of PAA. Moreover, SWCNTs films can act as second current collector to smooth the transfer of electron and $\mathrm{Li}^{+}$. As a result, due to the synergic effect of PAA-SWCNT interlayer, the assembled cell exhibited an initial capacity of $770 \mathrm{mAh}$

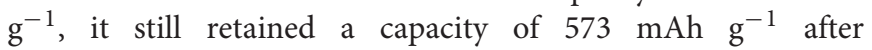
200 cycles at $1 \mathrm{C}$.

Apart from combined polymer with SWCNT, there are also researchers combined rGO with SWCNT as intermediate layer to anchor polysulfides (Hao J. et al., 2019). The composite membrane not only improve the internal electronic conductivity but also efficiently anchor polysulfides, resulting in an improved performance in $\mathrm{Li}-\mathrm{S}$ batteries.

\section{CONCLUSION AND OUTLOOK}

In summary, we briefly review the recent development of CNT-based materials, including heteroatom-doped CNTs, carbonaceous materials/CNT composites, and metal-based materials/

CNT composites, as interlayers for $\mathrm{Li}-\mathrm{S}$ batteries. Their nano/microstructure and electrochemical performances are intensively discussed. As we can see, even though the electrochemical properties of $\mathrm{Li}-\mathrm{S}$ batteries with CNT-based interlayer have been significantly improved, several problems still exist and need to be addressed before practical application of $\mathrm{Li}-\mathrm{S}$ batteries.

1. As mentioned above, CNTs-based materials are beneficial to immobilize the LiPSs when it is designed as an intercept layer, however, it should be noted that these materials could just relieve the shuttle effect to a certain degree physically or chemically, and the active materials still be possible to shuttle to the anode during the cycling. Moreover, the sulfur loading is normally about $1-2 \mathrm{mg} \mathrm{cm}^{-2}$ in most of above-mentioned work, and the highest loading does not exceed $10 \mathrm{mg} \mathrm{cm}^{-2}$. With gradually increased sulfur loading, despite the existence of intercept layers, the issues of active material loss and polysulfide shuttling are severe. Hence, it is imperative to develop new materials which have strong binding energy and interactions with polysulfides.

2. The mechanism of CNTs-based materials for immobilization and catalytic conversion of LiPSs and their phase transformation during cycling are not clear enough, and still need to be explored. In-operando techniques, such as in situ electron microscopy, and in situ X-ray 
technique, as well as synchron $\mathrm{X}$-ray based techniques, are very helpful to obtain time dependent information. So, more research using in-operando techniques need to conduct to get insight understanding of the CNTs-based materials as interlayers for $\mathrm{Li}-\mathrm{S}$ batteries.

3. Another issue to be tackled for practical application is lithium metal anode for lithium-sulfur batteries. There is always a problem in battery systems in which lithium metal exists: the formation and growth of lithium dendrites and the resulting low Coulombic efficiency and volume changes (Wang Y. et al., 2018; Wang G. et al., 2020; Zhao Q. et al., 2019). Therefore, in order to obtain a stable and safe lithium anode, a suitable electrolyte additive can be used. At present, the research on electrolyte additives has been highly advanced. Further, it is also possible to insert an artificial layer on the side of the lithium anode (Hao X. et al., 2019; Wang G. et al., 2020). However, there is little research on application of interlayers of CNTs-based composites in anodes, and this area requires further effort.

4. The reported literatures on CNTs-based materials coating layer/freestanding interlayers have developed many highloading sulfur cathodes with excellent performances. However, the introduction of a coating/freestanding interlayer will increase the inactive weight ratio of the whole battery. Therefore, the direction to balance the relationship between the introduced CNTs-based interlayers and the total energy densities of batteries will be very important in the development of high-energy $\mathrm{Li}-\mathrm{S}$ batteries.

\section{REFERENCES}

Ali, S., Rehman, S. A. U., Luan, H.-Y., Farid, M. U., and Huang, H. (2019). Challenges and opportunities in functional carbon nanotubes for membranebased water treatment and desalination. Sci. Total Environ. 646, 1126-1139. doi: 10.1016/j.scitotenv.2018.07.348

Cao, D. X., Jiao, Y. C., Cai, Q. F., Han, D. D., Zhang, Q., Ma, Y., et al. (2019) Stable lithium-sulfur full cells enabled by dual functional and interconnected mesocarbon arrays. J. Mater. Chem. A 7, 3289-3297. doi: 10.1039/c8ta1 $0351 \mathrm{~h}$

Chang, C.-H., Chung, S.-H., and Manthiram, A. (2015). Ultra-lightweight PANiNF/MWCNT-functionalized separators with synergistic suppression of polysulfide migration for Li-S batteries with pure sulfur cathodes. J. Mater. Chem. A 3, 18829-18834. doi: 10.1039/c5ta05053g

Chang, C.-H., Chung, S.-H., and Manthiram, A. (2016). Effective Stabilization of a High-Loading Sulfur Cathode and a Lithium-Metal Anode in Li-S Batteries Utilizing SWCNT-Modulated Separators. Small 12, 174-179. doi: 10.1002/smll. 201502505

Chang, C.-H., Chung, S.-H., Nanda, S., and Manthiram, A. (2017). A rationally designed polysulfide-trapping interface on the polymeric separator for highenergy Li-S batteries. Mater. Today Energy 6, 72-78. doi: 10.1016/j.mtener. 2017.09.001

Chen, A., Liu, W., Yan, J., and Liu, K. (2019). A novel separator modified by titanium dioxide nanotubes/carbon nanotubes composite for high performance lithium-sulfur batteries. Funct. Mater. Lett. 12:1950016. doi: 10.1142/ s1793604719500164

Chen, H., Zhang, B., Wang, X., Dong, P., Tong, H., Zheng, J.-C., et al. (2018). CNT-Decorated Na3V2(PO4)(3) Microspheres as a high-rate and cycle-stable cathode material for sodium ion batteries. ACS Appl. Mater. Interfaces 10, 3590-3595. doi: 10.1021/acsami.7b16402

\section{AUTHOR CONTRIBUTIONS}

YL and FR conceived the idea. HW and YL wrote the draft. All authors contributed to the writing, discussion, and revision of the final version of the manuscript.

\section{FUNDING}

This work was supported by the Program for Changjiang Scholars and Innovative Research Team in University (IRT_16R21), the Chinese 02 Special Fund (2017ZX02408003), the Scientific and Technological Project of Henan Province (182102210297), Open Fund of National Joint Engineering Research Center for Abrasion Control and Molding of Metal Materials (HKDNM201807), Eighth Postgraduate Innovation Foundation of Henan University of Science and Technology (CXJJ-2019KJ01), Science Foundation for Youths of Henan University of Science and Technology (2013QN006), the Student Research Training Plan of Henan University of Science and Technology (2020026), and the National Undergraduate Innovation and Entrepreneurship Training Program (202010464031).

\section{SUPPLEMENTARY MATERIAL}

The Supplementary Material for this article can be found online at: https://www.frontiersin.org/articles/10.3389/fenrg. 2020.585795/full\#supplementary-material

Chen, L., Yu, H., Li, W., Dirican, M., Liu, Y., and Zhang, X. (2020). Interlayer design based on carbon materials for lithium-sulfur batteries: a review. J. Mater. Chem. A 8, 10709-10735. doi: 10.1039/d0ta03028g

Chen, M., Zhao, S., Jiang, S., Huang, C., Wang, X., Yang, Z., et al. (2018). Suppressing the polysulfide shuttle effect by heteroatom-doping for highperformance lithium-sulfur batteries. ACS Sustain. Chem. Eng. 6, 7545-7557. doi: 10.1021/acssuschemeng.8b00273

Chen, P., Wang, Z., Zhang, B., Zhao, J., Liu, H., Guo, X., et al. (2020). Multifunctional $\mathrm{TiO} 2$ nanosheets/carbon nanotubes modified separator enhanced cycling performance for lithium-sulfur batteries. Int. J. Energy Res. 44, 32313240. doi: $10.1002 /$ er.5171

Chen, X., Huang, Y., Li, J., Wang, X., Zhang, Y., Guo, Y., et al. (2020). Bifunctional separator with sandwich structure for high-performance lithiumsulfur batteries. J. Colloid Interface Sci. 559, 13-20. doi: 10.1016/j.jcis.2019.10. 001

Chen, Y. T., Abbas, S. A., Kaisar, N., Wu, S. H., Chen, H. A., Boopathi, K. M., et al. (2019). Mitigating metal dendrite formation in lithium-sulfur batteries via morphology-tunable Graphene oxide interfaces. ACS Appl. Mater. Interfaces 11, 2060-2070. doi: 10.1021/acsami.8b18379

Cheng, X., Wang, W., Wang, A., Yuan, K., Jin, Z., Yang, Y., et al. (2016). Oxidized multiwall carbon nanotube modified separator for high performance lithiumsulfur batteries with high sulfur loading. RSC Adv. 6, 89972-89978. doi: 10 . $1039 /$ c6ra14581g

Cho, S. H., Cho, S. M., Bae, K. Y., Kim, B. H., Son, B. D., and Yoon, W. Y. (2019). Improving electrochemical properties of Lithium-Sulfur batteries by adding a catalyst-embedded interlayer. Electrochim. Acta 315, 33-40. doi: 10.1016/j. electacta.2019.05.062

Chung, S.-H., Han, P., and Manthiram, A. (2016). A polysulfide-trapping interface for electrochemically stable sulfur cathode development. ACS Appl. Mater. Interfaces 8, 4709-4717. doi: 10.1021/acsami.5b12012 
Chung, S.-H., and Manthiram, A. (2014). High-performance Li-S batteries with an ultra-lightweight MWCNT-Coated separator. J. Phys. Chemi. Lett. 5, 19781983. doi: $10.1021 /$ jz5006913

Ding, H., Zhang, Q., Liu, Z., Wang, J., Ma, R., Fan, L., et al. (2018). TiO2 quantum dots decorated multi-walled carbon nanotubes as the multifunctional separator for highly stable lithium sulfur batteries. Electrochim. Acta 284, 314-320. doi: 10.1016/j.electacta.2018.07.167

Ding, N., Zhou, L., Zhou, C., Geng, D., Yang, J., Chien, S. W., et al. (2016). Building better lithium-sulfur batteries: from LiNO3 to solid oxide catalyst. Sci. Rep. 6:33154.

Ding, X., Pan, Z., Liu, N., Li, L., Wang, X., Xu, G., et al. (2019). Freestanding carbon nanotube film for flexible Straplike Lithium/sulfur batteries. Chem. A Eur. J. 25, 3775-3780. doi: 10.1002/chem.201806408

Du, J., Ahmed, W., Xu, J., Zhang, M., Zhang, Z., Zhang, X., et al. (2020). Chainmail Catalyst of Fe3O4@C/CNTO-modified celgard separator with low metal loading for high-performance lithium-sulfur batteries. Chemistryselect 5 , 3757-3762. doi: 10.1002/slct.202000366

Fang, R., Li, G., Zhao, S., Yin, L., Du, K., Hou, P., et al. (2017). Single-wall carbon nanotube network enabled ultrahigh sulfur-content electrodes for highperformance lithium-sulfur batteries. Nano Energy 42, 205-214. doi: 10.1016/j. nanoen.2017.10.053

Gao, F., Yan, X., Li, X., Qiao, Y., Shang, H., Zhang, Y., et al. (2019a). A new finding on the enhancement of the ability of polysulfide adsorption of V2O5 by Doping Tungsten in Lithium-Sulfur Batteries. Energy Technol. 7:1900405. doi: 10.1002/ente.201900405

Gao, F., Yan, X., Wei, Z., Qu, M., and Fan, W. (2019b). Graphene/carbon nanotubes composite as a polysulfide trap for lithium-sulfur batteries. Int. J. Electrochem. Sci. 14, 3301-3314. doi: 10.20964/2019.04.16

Gao, G., Feng, W., Su, W., Wang, S., Chen, L., Li, M., et al. (2020). Preparation and Modification of MIL-101(Cr) Metal organic framework and its application in lithium-sulfur batteries. Int. J. Electrochem. Sci. 15, 1426-1436. doi: 10.20964/ 2020.02.26

Geng, Y., Ma, Z., Su, L., Sang, L., Ding, F., and Shao, G. (2020). A sandwichstructure composite carbon layer coated on separator to trap polysulfides for high-performance lithium sulfur batteries. J. Alloys Compd. 815:152189. doi: 10.1016/j.jallcom.2019.152189

Guan, B., Zhang, Y., Fan, L., Wu, X., Wang, M., Qiu, Y., et al. (2019). Blocking Polysulfide with Co2B@CNT via "Synergetic Adsorptive Effect" toward Ultrahigh-Rate Capability and Robust Lithium-Sulfur Battery. ACS Nano 13, 6742-6750. doi: 10.1021/acsnano.9b01329

Guan, Y., Li, W., Xie, X., Qu, W., Shen, J., Fu, K., et al. (2019). Preparation of TiO2/CNTs composite coated separator and its application in Li-S battery. Chem. J. Chin. Univ. Chin. 40, 536-541.

Guang, Z., Huang, Y., Chen, X., Sun, X., Wang, M., Feng, X., et al. (2019). Three-dimensional P-doped carbon skeleton with built-in Ni2P nanospheres as efficient polysulfides barrier for high-performance lithium-sulfur batteries. Electrochim. Acta 307, 260-268. doi: 10.1016/j.electacta.2019.03.190

Guo, D., Yang, M., Li, Y., Xue, Y., Liu, G., Wu, N., et al. (2020). Hydrogel-derived VPO4/porous carbon framework for enhanced lithium and sodium storage. Nanoscale 12, 3812-3819. doi: 10.1039/d0nr00460j

Guo, X., Zhang, Y.-Z., Zhang, F., Li, Q., Anjum, D. H., Liang, H., et al. (2019). A novel strategy for the synthesis of highly stable ternary SiOx composites for Li-ion-battery anodes. J. Mater. Chem. A 7, 15969-15974. doi: 10.1039/ c9ta04062e

Guo, Y., Xiao, J., Hou, Y., Wang, Z., and Jiang, A. (2017). Carbon nanotube doped active carbon coated separator for enhanced electrochemical performance of lithium-sulfur batteries. J. Mater. Sci. Mater. Electron. 28, 17453-17460. doi: 10.1007/s10854-017-7679-7

Hao, J., Pan, Y., Chen, W., Zhu, X., Zhou, Y., and Chou, S. (2019). Improving the Li-S battery performance by applying a combined interface engineering approach on the Li2S cathode. J. Mater. Chem. A 7, 27247-27255. doi: 10.1039/ c9ta10301e

Hao, X., Zhao, Q., Su, S., Zhang, S., Ma, J., Shen, L., et al. (2019). Constructing Multifunctional Interphase between Li1.4Al0.4Ti1.6(PO4)(3) and Li Metal by Magnetron Sputtering for Highly Stable Solid-State Lithium Metal Batteries. Adv. Energy Mater. 9:1901604. doi: 10.1002/aenm.201901604

Hong, X.-J., Song, C.-L., Yang, Y., Tan, H.-C., Li, G.-H., Cai, Y.-P., et al. (2019). Cerium based metal-organic frameworks as an efficient separator coating catalyzing the conversion of polysulfides for high performance lithium-sulfur batteries. ACS Nano 13, 1923-1931.

Huang, J.-Q., Chong, W. G., Zheng, Q., Xu, Z.-L., Cui, J., Yao, S., et al. (2018). Understanding the roles of activated porous carbon nanotubes as sulfur support and separator coating for lithium-sulfur batteries. Electrochim. Acta 268, 1-9. doi: 10.1016/j.electacta.2018.02.096

Huang, J.-Q., Xu, Z.-L., Abouali, S., Garakani, M. A., and Kim, J.-K. (2016). Porous graphene oxide/carbon nanotube hybrid films as interlayer for lithium-sulfur batteries. Carbon 99, 624-632. doi: 10.1016/j.carbon.2015.12.081

Huang, J. Q., Zhuang, T. Z., Zhang, Q., Peng, H. J., Chen, C. M., and Wei, F. (2015). Permselective graphene oxide membrane for highly stable and antiself-discharge lithium-sulfur batteries. ACS Nano 9, 3002-3011. doi: 10.1021/ nn507178a

Huang, Y., Sun, X., Wang, J., Li, X., Chen, W., Wei, C., et al. (2019). Hydroxylated sandwich-structure interlayer as a polysulfide reservoir for lithium-sulfur battery. J. Alloys Compd. 776, 187-193. doi: 10.1016/j.jallcom.2018. 10.146

Hwang, J.-Y., Kim, H. M., Lee, S.-K., Lee, J.-H., Abouimrane, A., Khaleel, M. A., et al. (2016). High-energy, high-rate, lithium-sulfur batteries: synergetic effect of hollow TiO2-webbed carbon nanotubes and a dual functional carbon-paper interlayer. Adv. Energy Mater. 6:1501480. doi: 10.1002/aenm.201501480

Jeong, Y. C., Kim, J. H., Kwon, S. H., Oh, J. Y., Park, J., Jung, Y., et al. (2017). Rational design of exfoliated 1T MoS2@CNT-based bifunctional separators for lithium sulfur batteries. J. Mater. Chem. A 5, 23909-23918. doi: 10.1039/ c7ta08153g

Jiang, S., Chen, M., Wang, X., Wu, Z., Zeng, P., Huang, C., et al. (2018). MoS2-Coated N-doped Mesoporous Carbon Spherical Composite Cathode and CNT/Chitosan modified separator for advanced lithium sulfur batteries. ACS Sustain. Chem. Eng. 6:16828. doi: 10.1021/acssuschemeng.8b04157

Jiang, S., Chen, M., Wang, X., Zeng, P., Li, Y., Liu, H., et al. (2019). A tin disulfide nanosheet wrapped with interconnected carbon nanotube networks for application of lithium sulfur batteries. Electrochim. Acta 313, 151-160. doi: 10.1016/j.electacta.2019.05.001

Jiao, L., Wu, S., Tao, Y., Lv, W., Zhang, C., Ling, G., et al. (2019). Interlayers for lithium-based batteries. Energy Storage Mater. 23, 112-136.

Jin, Q., Zhang, N., Zhu, C. C., Gao, H., and Zhang, X. T. (2018). Rationally designing S/Ti3C2Tx as a cathode material with an interlayer for high-rate and long-cycle lithium-sulfur batteries. Nanoscale 10, 16935-16942. doi: 10.1039/ c8nr05749d

Kaiser, M. R., Wang, J., Liang, X., Liu, H.-K., and Dou, S.-X. (2015). A systematic approach to high and stable discharge capacity for scaling up the lithium-sulfur battery. J. Power Sources 279, 231-237. doi: 10.1016/j.jpowsour.2014.12.098

Kiai, M. S., and Kizil, H. (2019). Enhanced performance of Li-S battery with polymer doped potassium functionalized graphene interlayers as effective polysulfide barrier. J. Electroanal. Chem. 851:113405. doi: 10.1016/j.jelechem. 2019.113405

Kim, D. S., Bae, J., Kwon, S. H., Hur, J., Lee, S. G., and Kim, I. T. (2020). Synergistic effect of antimony-triselenide on addition of conductive hybrid matrix for highperformance lithium-ion batteries. J. Alloys Compd. 828:154410. doi: 10.1016/ j.jallcom.2020.154410

Kim, H. M., Hwang, J.-Y., Manthiram, A., and Sun, Y.-K. (2016). High performance lithium-sulfur batteries with a self-assembled multiwall carbon nanotube interlayer and a robust electrode electrolyte interface. ACS Appl. Mater. Interfaces 8, 983-987. doi: 10.1021/acsami.5b10812

Kim, J. H., Seo, J., Choi, J., Shin, D., Carter, M., Jeon, Y., et al. (2016). Synergistic ultrathin functional polymer-coated carbon nanotube interlayer for high performance lithium-sulfur batteries. ACS Appl. Mater. Interfaces 8, 20092-20099. doi: 10.1021/acsami.6b06190

Kim, P. J. H., Kim, K., and Pol, V. G. (2018). Towards highly stable lithium sulfur batteries: surface functionalization of carbon nanotube scaffolds. Carbon 131, 175-183. doi: 10.1016/j.carbon.2018.01.100

Kong, L., Peng, H.-J., Huang, J.-Q., Zhu, W., Zhang, G., Zhang, Z.-W., et al. (2017). Beaver-dam-like membrane: a robust and sulphifilic MgBO2(OH)/CNT/PP nest separator in Li-S batteries. Energy Storage Mater. 8, 153-160. doi: 10.1016/ j.ensm.2017.05.009

Kong, W., Wang, D., Yan, L., Luo, Y., Jiang, K., Li, Q., et al. (2018). Ultrathin HfO2-modified carbon nanotube films as efficient polysulfide barriers for Li-S batteries. Carbon 139, 896-905. doi: 10.1016/j.carbon.2018.07.063 
Kong, W., Yan, L., Luo, Y., Wang, D., Jiang, K., Li, Q., et al. (2017). Ultrathin $\mathrm{MnO} / \mathrm{Graphene}$ Oxide/Carbon nanotube interlayer as efficient polysulfidetrapping shield for high-performance Li-S batteries. Adv. Funct. Mater. 27:1606663. doi: 10.1002/adfm.201606663

Kumar, G. G., Chung, S.-H., Kumar, T. R., and Manthiram, A. (2018). Threedimensional graphene-carbon nanotube-Ni hierarchical architecture as a polysulfide trap for lithium-sulfur batteries. ACS Appl. Mater. Interfaces 10, 20627-20634. doi: 10.1021/acsami.8b06054

Kumar, S., Nehra, M., Kedia, D., Dilbaghi, N., Tankeshwar, K., and Kim, K.H. (2018). Carbon nanotubes: a potential material for energy conversion and storage. Prog. Energy Combust. Sci. 64, 219-253. doi: 10.1016/j.pecs.2017.10.005

Lee, C.-L., and Kim, I.-D. (2015). A hierarchical carbon nanotube-loaded glassfilter composite paper interlayer with outstanding electrolyte uptake properties for high-performance lithium-sulphur batteries. Nanoscale 7, 10362-10367. doi: $10.1039 / \mathrm{c} 5 \mathrm{nr} 02637 \mathrm{~g}$

Lee, D. H., Ahn, J. H., Park, M.-S., Eftekhari, A., and Kim, D.-W. (2018). Metal-organic framework/carbon nanotube-coated polyethylene separator for improving the cycling performance of lithium-sulfur cells. Electrochim. Acta 283, 1291-1299. doi: 10.1016/j.electacta.2018.07.031

Lee, D. K., Kim, S. J., Kim, Y.-J., Choi, H., Kim, D. W., Jeon, H.-J., et al. (2019). Graphene oxide/carbon nanotube bilayer flexible membrane for high-performance Li-S batteries with superior physical and electrochemical properties. Adv. Mater. Interfaces 6:1801992. doi: 10.1002/admi.201801992

Lee, Y.-H., Kim, J.-H., Kim, J.-H., Yoo, J.-T., and Lee, S.-Y. (2018). Spiderwebmimicking anion-exchanging separators for Li-S batteries. Adv. Funct. Mater. 28:1870293. doi: $10.1002 /$ adfm.201870293

Li, J., Jiang, Y., Qin, F., Fang, J., Zhang, K., and Lai, Y. (2018). Magnetronsputtering MoS2 on carbon paper and its application as interlayer for highperformance lithium sulfur batteries. J. Electroanal. Chem. 823, 537-544. doi: 10.1016/j.jelechem.2018.07.006

Li, M., Feng, W., and Wang, X. (2020a). Complex hollow structures of Cobalt(II) sulfide as a cathode for lithium-sulfur batteries. Int. J. Electrochem. Sci. 15, 526-534. doi: $10.20964 / 2020.01 .77$

Li, M., Wahyudi, W., Kumar, P., Wu, F., Yang, X., Li, H., et al. (2017). Scalable approach to construct free-standing and flexible carbon networks for lithiumsulfur battery. ACS Appl. Mater. Interfaces 9, 8047-8054.

Li, N., Cao, W., Liu, Y., Ye, H., and Han, K. (2019a). Impeding polysulfide shuttling with a three-dimensional conductive carbon nanotubes/MXene framework modified separator for highly efficient lithium-sulfur batteries. Colloids Surf. A Physicochem. Eng. Aspects 573, 128-136. doi: 10.1016/j.colsurfa.2019.04.054

Li, N., Chen, Z., Chen, F., Hu, G., Wang, S., Sun, Z., et al. (2019b). From interlayer to lightweight capping layer: rational design of mesoporous $\mathrm{TiO} 2$ threaded with CNTs for advanced Li-S batteries. Carbon 143, 523-530. doi: 10.1016/j.carbon. 2018.11.064

Li, N., Ma, X., Ye, H., Wang, S., and Han, K. (2019c). Carbon nanotube-modified separator for lithium-sulfur batteries: effects of mass loading and adding polyvinylpyrrolidone on electrochemical performance. J. Phys. Chem. Solids 134, 69-76. doi: 10.1016/j.jpcs.2019.05.045

Li, N., Xie, Y., Peng, S., Xiong, X., and Han, K. (2020b). Ultra-lightweight Ti3C2Tx MXene modified separator for Li-S batteries: thickness regulation enabled polysulfide inhibition and lithium ion transportation. J. Energy Chem. 42, 116-125. doi: 10.1016/j.jechem.2019.06.014

Li, R., Sun, X., Zou, J., He, Q., and Xu, Y. (2019d). New-type SiO2/AP interlayer for inhibiting shuttle effect of Li-S battery. Mater. Res. Express 6:1801992.

Li, S., Zhang, H., Chen, W., Zou, Y., Yang, H., Yang, J., et al. (2020c). Toward commercially viable Li-S batteries: overall performance improvements enabled by a multipurpose interlayer of hyperbranched polymer-grafted carbon nanotubes. ACS Appl. Mater. Interfaces 12, 25767-25774. doi: 10.1021/acsami. $0 \mathrm{c} 03182$

Li, S., Zhang, W., Zheng, J., Lv, M., Song, H., and Du, L. (2020d). Inhibition of polysulfide shuttles in Li-S batteries: modified separators and solid-state electrolytes. Adv. Energy Mater. 28:2000779. doi: 10.1002/aenm.202000779

Li, Y., Li, X., Hao, Y., Kakimov, A., Li, D., Sun, Q., et al. (2020e). $\beta$-FeOOH interlayer with abundant oxygen vacancy toward boosting catalytic effect for lithium sulfur batteries. Front. Chem. 8:309. doi: 10.3389/fchem.2020.00309

Li, Y., Zhai, X., Liu, Y., Wei, H., Ma, J., Chen, M., et al. (2020f). WO3-based materials as electrocatalysts for hydrogen evolution reaction. Front. Mater. 7:105. doi: $10.3389 /$ fmats.2020.00105
Li, Y., Zhou, P., Li, H., Gao, T., Zhou, L., Zhang, Y., et al. (2020g). A freestanding flexible single-atom cobalt-based multifunctional interlayer toward reversible and durable lithium-sulfur batteries. Small Methods 4:1900701. doi: 10.1002/ smtd.201900701

Li, Z., Tang, L., Liu, X., Song, T., Xu, Q., Liu, H., et al. (2019e). A polar TiO/MWCNT coating on a separator significantly suppress the shuttle effect in a lithium-sulfur battery. Electrochim. Acta 310, 1-12. doi: 10.1016/j.electacta. 2019.04.057

Li, Z., Xu, J., Wang, J., Niu, D., Hu, S., and Zhang, X. (2019f). Well-dispersed amorphous $\mathrm{Ta} 2 \mathrm{O} 5$ chemically grafted onto multi-walled carbon nanotubes for high-performance lithium sulfur battery. Int. J. Electrochem. Sci. 14, 6628-6642. doi: 10.20964/2019.07.39

Liu, B., Wang, S., Wu, X., Liu, Z., Gao, Z., Li, C., et al. (2018). Carbon nanotube/zirconia composite-coated separator for a high-performance rechargeable lithium-sulfur battery. AIP Adv. 8:105315. doi: 10.1063/1.5044486

Liu, B., Wu, X., Wang, S., Tang, Z., Yang, Q., Hu, G.-H., et al. (2017). Flexible carbon nanotube modified separator for high-performance lithium-sulfur batteries. Nanomaterials 7:196. doi: 10.3390/nano7080196

Liu, G., Cui, J., Luo, R., Liu, Y., Huang, X., Wu, N., et al. (2019a). 2D MoS2 grown on biomass-based hollow carbon fibers for energy storage. Appl. Surf. Sci. 469, 854-863. doi: 10.1016/j.apsusc.2018.11.067

Liu, G., Wu, H.-H., Meng, Q., Zhang, T., Sun, D., Jin, X., et al. (2020). Role of the anatase/TiO2(B) heterointerface for ultrastable high-rate lithium and sodium energy storage performance. Nanoscale Horiz. 5, 150-162. doi: 10.1039/ c9nh00402e

Liu, M., Yang, Z., Sun, H., Lai, C., Zhao, X., Peng, H., et al. (2016). A hybrid carbon aerogel with both aligned and interconnected pores as interlayer for high-performance lithium-sulfur batteries. Nano Res. 9, 3735-3746. doi: 10. 1007/s12274-016-1244-1

Liu, Y., Wang, H., Yang, K., Yang, Y., Ma, J., Pan, K., et al. (2019b). Enhanced Electrochemical Performance of $\mathrm{Sb} 2 \mathrm{O} 3$ as an Anode for Lithium-Ion Batteries by a Stable Cross-Linked Binder. Appl. Sci. Basel 9:2677. doi: 10.3390/ app9132677

Liu, Y., Wang, Y., Wang, F., Lei, Z., Zhang, W., Pan, K., et al. (2019c). Facile synthesis of antimony tungstate nanosheets as anodes for lithium-ion batteries. Nanomaterials 9:1689. doi: 10.3390/nano9121689

Lu, Q., Zou, X., Ran, R., Zhou, W., Liao, K., and Shao, Z. (2019). An "electronegative" bifunctional coating layer: simultaneous regulation of polysulfide and Li-ion adsorption sites for long-cycling and "dendrite-free", Li-S batteries. J. Mater. Chem. A 7, 22463-22474. doi: 10.1039/c9ta07999h

Luo, L., Chung, S.-H., and Manthiram, A. (2016). A trifunctional multi-walled carbon nanotubes/polyethylene glycol (MWCNT/PEG)-coated separator through a layer-by-layer coating strategy for high-energy Li-S batteries. J. Mater. Chem. A 4, 16805-16811. doi: 10.1039/c6ta07709a

Luo, L., Qin, X., Wu, J., Liang, G., Li, Q., Liu, M., et al. (2018). An interwoven MoO3@CNT scaffold interlayer for high-performance lithium-sulfur batteries. J. Mater. Chem. A 6, 8612-8619. doi: 10.1039/c8ta01726c

Luo, R., Lu, Y., Hou, X., Yu, Q., Peng, T., Yan, H., et al. (2017). Encapsulation of $\mathrm{Se} / \mathrm{C}$ into ultra-thin $\mathrm{Ni}(\mathrm{OH})(2)$ nanosheets as cathode materials for lithiumselenium batteries. J. Solid State Electrochem. 21, 3611-3618. doi: 10.1007/ s10008-017-3696-y

Luo, Y., Luo, N., Kong, W., Wu, H., Wang, K., Fan, S., et al. (2018). Multifunctional interlayer based on molybdenum diphosphide catalyst and carbon nanotube film for lithium-sulfur batteries. Small 14:1702853. doi: 10 . 1002/smll.201702853

Ma, J., Guo, X., Xue, H., Pan, K., Liu, C., and Pang, H. (2020a). Niobium/tantalumbased materials: synthesis and applications in electrochemical energy storage. Chem. Eng. J. 380:122428. doi: 10.1016/j.cej.2019.122428

Ma, J., Ren, F., Wang, G., Xiong, Y., Li, Y., and Wen, J. (2017). Electrochemical performance of melt-spinning Al-Mg-Sn based anode alloys. Int. J. Hydrogen Energy 42, 11654-11661. doi: 10.1016/j.ijhydene.2017.02.185

Ma, J., Wei, H., Liu, Y., Ren, X., Li, Y., Wang, F., et al. (2020b). Application of Co3O4-based materials in electrocatalytic hydrogen evolution reaction: a review. Int. J. Hydrogen Energy 45, 21205-21220. doi: 10.1016/j.ijhydene.2020. 05.280

Ma, J., Wen, J., Li, Q., and Zhang, Q. (2013). Electrochemical polarization and corrosion behavior of Al-Zn-In based alloy in acidity and alkalinity solutions. Int. J. Hydrogen Energy 38, 14896-14902. doi: 10.1016/j.ijhydene.2013.09.046 
Ma, J., Zhang, Y., Qin, C., Ren, F., and Wang, G. (2020c). Effects of polystyrene sulfonate/graphene and $\mathrm{Mn3O} 4$ /graphene on property of aluminum(zinc)-air batteries. Int. J. Hydrogen Energy 45, 13025-13034. doi: 10.1016/j.ijhydene. 2020.02.222

Ma, X., Xiong, X., Zou, P., Liu, W., Wang, F., Liang, L., et al. (2019). General and Scalable Fabrication of Core-Shell Metal Sulfides@C Anchored on 3D N-Doped Foam toward Flexible Sodium Ion Batteries. Small 15:1903259. doi: 10.1002/ smll.201903259

Manoj, M., Ashraf, C. M., Jasna, M., Anilkumar, K. M., Jinisha, B., Pradeep, V.S., et al. (2019). Biomass-derived, activated carbon-sulfur composite cathode with a bifunctional interlayer of functionalized carbon nanotubes for lithiumsulfur cells. J. Colloid Interface Sci. 535, 287-299. doi: 10.1016/j.jcis.2018. 09.096

Manoj, M., Jasna, M., Anilkumar, K. M., Abhilash, A., Jinisha, B., Pradeep, V. S., et al. (2018a). Sulfur-polyaniline coated mesoporous carbon composite in combination with carbon nanotubes interlayer as a superior cathode assembly for high capacity lithium-sulfur cells. Appl. Surf. Sci. 458, 751-761. doi: 10.1016/ j.apsusc. 2018.07 .113

Manoj, M., Jasna, M., and Jayalekshmi, S. (2018b). “Activated Carbon-Sulfur composite with PEDOT: PSS-CNT interlayer as cathode material for LithiumSulfur batteries," in Proceedings of the PIE 10725 Low-Dimensional Materials and Devices, Vol. 1075, eds N. P. Kobayashi, A. A. Talin, M. S. Islam, and A. V. Davydov (San Diego, CA: SPIE).

Pan, K., Wang, F., Wei, S., Siyal, S. H., Ren, Y., Xu, L., et al. (2020). Lowtemperature solution synthesis and characterization of enhanced titanium dioxide photocatalyst on tailored mesoporous $\gamma$-Al2O3 support. Compos. Commun. 19, 82-89. doi: 10.1016/j.coco.2020.02.009

Pan, S., Yin, Z., Cheng, Q., Zhang, G., Yu, X., Pan, Z., et al. (2020). Bifunctional TiS $2 / C N T$ as efficient polysulfide barrier to improve the performance of lithium -sulfur battery. J. Alloys Compd. 832:154947. doi: 10.1016/j.jallcom. 2020.154947

Pang, Y., Wei, J., Wang, Y., and Xia, Y. (2018). Synergetic Protective Effect of the Ultralight MWCNTs/NCQDs modified separator for highly stable lithiumsulfur batteries. Adv. Energy Mater. 8:e1702288.

Paolella, A., Demers, H., Chevallier, P., Gagnon, C., Girard, G., Delaporte, N., et al. (2019). A platinum nanolayer on lithium metal as an interfacial barrier to shuttle effect in Li-S batteries. J. Power Sources 427, 201-206. doi: 10.1016/j. jpowsour.2019.04.078

Pei, F., Fu, A., Ye, W., Peng, J., Fang, X., Wang, M.-S., et al. (2019). Robust lithium metal anodes realized by Lithiophilic 3D porous current collectors for constructing high-energy lithium-sulfur batteries. ACS Nano 13, 8337-8346. doi: 10.1021/acsnano.9b03784

Peng, Y., Wen, Z., Liu, C., Zeng, J., Wang, Y., and Zhao, J. (2019). Refining Interfaces between Electrolyte and Both Electrodes with Carbon Nanotube Paper for High-Loading Lithium-Sulfur Batteries. ACS Appl. Mater. Interfaces 11, 6986-6994. doi: 10.1021/acsami.8b19866

Ponraj, R., Kannan, A. G., Ahn, J. H., Lee, J. H., Kang, J., Han, B., et al. (2017). Effective Trapping of Lithium Polysulfides using a functionalized carbon nanotube-coated separator for lithium-sulfur cells with enhanced cycling stability. ACS Appl. Mater. Interfaces 9, 38445-38454. doi: 10.1021/acsami. $7 \mathrm{~b} 10641$

Rui, L. I., Sun, X., Huang, Y., Zou, J., He, Q., and Xu, Y. (2019). SMAP interlayer for inhibiting shuttle effect of lithium-sulfur battery. Vacuum 168:108820. doi: 10.1016/j.vacuum.2019.108820

Shi, H., Zhao, X., Wu, Z.-S., Dong, Y., Lu, P., Chen, J., et al. (2019). Free-standing integrated cathode derived from 3D graphene/carbon nanotube aerogels serving as binder-free sulfur host and interlayer for ultrahigh volumetricenergy-density lithium-sulfur batteries. Nano Energy 60, 743-751. doi: 10.1016/ j.nanoen.2019.04.006

Shi, L., Zeng, F., Cheng, X., Lam, K. H., Wang, W., Wang, A., et al. (2018). Enhanced performance of lithium-sulfur batteries with high sulfur loading utilizing ion selective MWCNT/SPANI modified separator. Chem. Eng. J. 334, 305-312. doi: 10.1016/j.cej.2017.08.015

Son, B. D., Cho, S. H., Bae, K. Y., Kim, B. H., and Yoon, W. Y. (2019). Dual functional effect of the ferroelectricity embedded interlayer in lithium sulfur battery. J. Power Sources 419, 35-41. doi: 10.1016/j.jpowsour.2019.02.014

Song, C., Feng, W., Wang, X., and Shi, Z. (2020). Enhanced electrochemical performance of Li1.2Mn0.54Ni0.13 Co0.13O2 cathode material with bamboo essential oil. Ionics 26, 661-672. doi: 10.1007/s11581-019-03233-9
Song, C.-L., Li, G.-H., Yang, Y., Hong, X.-J., Huang, S., Zheng, Q.-F., et al. (2020). 3D catalytic MOF-based nanocomposite as separator coatings for highperformance Li-S battery. Chem. Eng. J. 381:122701. doi: 10.1016/j.cej.2019. 122701

Su, Y.-S., and Manthiram, A. (2012). A new approach to improve cycle performance of rechargeable lithium-sulfur batteries by inserting a freestanding MWCNT interlayer. Chem. Commun. 48, 8817-8819. doi: 10.1039/ c2cc33945e

Sui, D., Xu, L., Zhang, H., Sun, Z., Kan, B., Ma, Y., et al. (2020). A 3D cross-linked graphene-based honeycomb carbon composite with excellent confinement effect of organic cathode material for lithium-ion batteries. Carbon 157, 656662. doi: 10.1016/j.carbon.2019.10.106

Sun, L., Kong, W., Li, M., Wu, H., Jiang, K., Li, Q., et al. (2016). Cross-stacked carbon nanotube film as an additional built-in current collector and adsorption layer for high-performance lithium sulfur batteries. Nanotechnology 27:075401. doi: 10.1088/0957-4484/27/7/075401

Sun, X., Huang, Y., Chen, M., and Dou, W. (2018). Double interlayers to improve cycle performance for Li-S batteries by Using Multiwall carbon nanotubes/reduced graphene oxide. Ind. Eng. Chem. Res. 57, 6741-6745. doi: 10.1021/acs.iecr.8b01360

Sun, Z., Guo, Y., Li, B., Tan, T., and Zhao, Y. (2019a). ZnO/carbon nanotube/reduced graphene oxide composite film as an effective interlayer for lithium/sulfur batteries. Solid State Sci. 95:105924. doi: 10.1016/j. solidstatesciences.2019.06.013

Sun, Z., Wang, T., Zhang, Y., Kempa, K., and Wang, X. (2019b). Boosting the electrochemical performance of lithium/sulfur batteries with the carbon nanotube/Fe3O4 coated by carbon modified separator. Electrochim. Acta 327:134843.

Sun, Z., Xie, C., Fan, Z., Shen, F., Yin, Y., Niu, C., et al. (2020). Ultrathin dense double-walled carbon nanotube membrane for enhanced lithium-sulfur batteries. J. Nanopart. Res. 22:160.

Tan, L., Li, X., Wang, Z., Guo, H., Wang, J., and An, L. (2018). Multifunctional separator with porous carbon/multi-walled carbon nanotube coating for advanced lithium-sulfur batteries. Chemelectrochem 5, 71-77. doi: 10.1002/celc. 201700986

Tian, W., Xi, B., Mao, H., Zhang, J., Feng, J., and Xiong, S. (2018). Systematic Exploration of the Role of a Modified Layer on the Separator in the Electrochemistry of Lithium-Sulfur Batteries. ACS Appl. Mater. Interfaces 10, 30306-30313. doi: 10.1021/acsami.8b08438

Wang, A., Xu, G., Ding, B., Chang, Z., Wang, Y., Dou, H., et al. (2017). Highly conductive and lightweight composite film as polysulfide reservoir for highperformance lithium-sulfur batteries. Chemelectrochem 4, 362-368. doi: 10 . 1002/celc.201600579

Wang, F., Liu, Y., Wei, H., Wang, G., Ren, F., Liu, X., et al. (2020). Graphene induced growth of $\mathrm{Sb}_{2} \mathrm{WO}_{6}$ nanosheets for high- performance pseudocapacitive lithium -ion storage. J. Alloys Compd. 839:155614. doi: 10. 1016/j.jallcom.2020.155614

Wang, F., Liu, Y., Zhao, Y., Wang, Y., Wang, Z., Zhang, W., et al. (2018). Facile synthesis of two-dimensional porous $\mathrm{MgCo} 2 \mathrm{O} 4$ nanosheets as anode for lithium-ion batteries. Appl. Sci. Basel 8:22. doi: 10.3390/app8010022

Wang, G., Chen, C., Chen, Y., Kang, X., Yang, C., Wang, F., et al. (2020). Self-stabilized and strongly adhesive supramolecular polymer protective layer enables ultrahigh-rate and large-capacity lithium-metal anode. Angew. Chem. Int. Ed. 59, 2055-2060. doi: 10.1002/anie.201913351

Wang, G., Lai, Y., Zhang, Z., Li, J., and Zhang, Z. (2015). Enhanced rate capability and cycle stability of lithium-sulfur batteries with a bifunctional MCNT@PEGmodified separator. J. Mater. Chem. A 3, 7139-7144. doi: 10.1039/c4ta07133f

Wang, J., Qin, W., Zhu, X., and Teng, Y. (2020). Covalent organic frameworks (COF)/CNT nanocomposite for high performance and wide operating temperature lithium-sulfur batteries. Energy 199:117372. doi: 10.1016/j.energy. 2020.117372

Wang, J., Sun, X., Chen, W., Li, X., Huang, Y., Wei, C., et al. (2018). Electrochemical performance of hydroxylated multi-walled carbon nanotube sandwich separator in lithium-sulfur battery. Chem. J. Chin. Univ. Chin. 39, 1782-1789.

Wang, L., He, Y.-B., Shen, L., Lei, D., Ma, J., Ye, H., et al. (2018). Ultra-small selfdischarge and stable lithium-sulfur batteries achieved by synergetic effects of multicomponent sandwich-type composite interlayer. Nano Energy 50, 367375. doi: 10.1016/j.nanoen.2018.05.043 
Wang, R., Cao, X., Zhao, D., Zhu, L., Xie, L., Liu, J., et al. (2020). Wet-chemistry synthesis of Li4Ti5O12 as anode materials rendering high-rate $\mathrm{Li}$-ion storage. Int. J. Energy Res. 44, 4211-4223. doi: 10.1002/er.5020

Wang, S., Li, X., Zhang, Y., Zheng, W., Dai, Y., and He, G. (2020). Highly efficient polysulfide trapping and ion transferring within a hierarchical porous membrane interlayer for high-energy lithium-sulfur batteries. ACS Appl. Energy Mater. 3, 5050-5057. doi: 10.1021/acsaem.0c00629

Wang, W., Sun, K., and Liu, H. (2020). Effects of different aluminum sources on morphologies and properties of ceramic floor tiles from red mud. Construct. Build. Mater. 241:118119. doi: 10.1016/j.conbuildmat.2020.118119

Wang, X., Hao, X., Cai, D., Zhang, S., Xia, X., and Tu, J. (2020). An ultraviolet polymerized 3D gel polymer electrolyte based on multi-walled carbon nanotubes doped double polymer matrices for lithium-sulfur batteries. Chem. Eng. J. 382:122714. doi: 10.1016/j.cej.2019.122714

Wang, X., Yang, C., Xiong, X., Chen, G., Huang, M., Wang, J.-H., et al. (2019). A robust sulfur host with dual lithium polysulfide immobilization mechanism for long cycle life and high capacity Li-S batteries. Energy Storage Mater. 16, 344-353. doi: 10.1016/j.ensm.2018.06.015

Wang, Y., Liu, W., Liu, R., Pan, P., Suo, L., Chen, J., et al. (2019). Inhibiting polysulfide shuttling using dual-functional nanowire/nanotube modified layers for highly stable lithium-sulfur batteries. New J. Chem. 43, 14708-14713. doi: 10.1039/c9nj03320c

Wang, Y., Wang, Z., Lei, D., Lv, W., Zhao, Q., Ni, B., et al. (2018). Spherical Li Deposited inside 3D Cu Skeleton as Anode with Ultrastable Performance. ACS Appl. Mater. Interfaces 10, 20244-20249. doi: 10.1021/acsami.8b04881

Wei, H., Ding, Y., Li, H., Zhang, Q., Hu, N., Wei, L., et al. (2019). MoS2 quantum dots decorated reduced graphene oxide as a sulfur host for advanced lithiumsulfur batteries. Electrochim. Acta 327:134994. doi: 10.1016/j.electacta.2019. 134994

Wei, L., Li, W., Zhao, T., Zhang, N., Li, L., Wu, F., et al. (2020). Cobalt nanoparticles shielded in $\mathrm{N}$-doped carbon nanotubes for high areal capacity Li-S batteries. Chem. Commun. 56, 3007-3010. doi: 10.1039/c9cc08218b

Wu, F., Zhao, S., Chen, L., Lu, Y., Su, Y., Jia, Y., et al. (2018). Metal-organic frameworks composites threaded on the CNT knitted separator for suppressing the shuttle effect of lithium sulfur batteries. Energy Storage Mater. 14, 383-391. doi: 10.1016/j.ensm.2018.06.009

Wu, H., Huang, Y., Zhang, W., Sun, X., Yang, Y., Wang, L., et al. (2017). Lock of sulfur with carbon black and a three-dimensional graphene@carbon nanotubes coated separator for lithium-sulfur batteries. J. Alloys Compd. 708, 743-750. doi: 10.1016/j.jallcom.2017.03.047

Wu, N., Qiao, X. G., Shen, J. K., Liu, G. L., Sun, T., Wu, H., et al. (2019a). Anatase inverse opal TiO2-x@N-doped C induced the dominant pseudocapacitive effect for durable and fast lithium/sodium storage. Electrochim. Acta 299, 540-548. doi: 10.1016/j.electacta.2019.01.040

Wu, N., Shen, J., Sun, L., Yuan, M., Shao, Y., Ma, J., et al. (2019b). Hierarchical $\mathrm{N}$-doped graphene coated 1D cobalt oxide microrods for robust and fast lithium storage at elevated temperature. Electrochim. Acta 310, 70-77. doi: 10.1016/j. electacta.2019.04.115

Xiang, K., Wen, X., Hu, J., Wang, S., and Chen, H. (2019). Rational fabrication of nitrogen and sulfur Codoped Carbon Nanotubes/MoS2 for high-performance lithium-sulfur batteries. Chemsuschem 12, 3602-3614. doi: 10.1002/cssc. 201900929

Xie, K., Yuan, K., Zhang, K., Shen, C., Lv, W., Liu, X., et al. (2017). Dual functionalities of carbon nanotube films for dendrite-free and high energyhigh power lithium-sulfur batteries. ACS Appl. Mater. Interfaces 9, 4605-4613. doi: 10.1021/acsami.6b14039

Xu, G., Yuan, J., Tao, X., Ding, B., Dou, H., Yan, X., et al. (2015). Absorption mechanism of carbon-nanotube paper-titanium dioxide as a multifunctional barrier material for lithium-sulfur batteries. Nano Res. 8, 3066-3074. doi: 10.1007/s12274-015-0812-0

Xu, J., Zhang, Q., Liang, X., Yan, J., Liu, J., and Wu, Y. (2020). A multifunctional separator based on scandium oxide nanocrystal decorated carbon nanotubes for high performance lithium-sulfur batteries. Nanoscale 12, 6832-6843. doi: 10.1039/d0nr00160k

Xu, Q., Hu, G. C., Bi, H. L., and Xiang, H. F. (2015). A trilayer carbon nanotube/Al2O3/polypropylene separator for lithium-sulfur batteries. Ionics 21, 981-986. doi: 10.1007/s11581-014-1263-4

Yan, L., Luo, N., Kong, W., Luo, S., Wu, H., Jiang, K., et al. (2018). Enhanced performance of lithium-sulfur batteries with an ultrathin and lightweight
MoS2/carbon nanotube interlayer. J. Power Sources 389, 169-177. doi: 10.1016/ j.jpowsour.2018.04.015

Yang, L., Li, G., Jiang, X., Zhang, T., Lin, H., and Lee, J. Y. (2017). Balancing the chemisorption and charge transport properties of the interlayer in lithiumsulfur batteries. J. Mater. Chem. A 5, 12506-12512. doi: 10.1039/c7ta01 $352 \mathrm{c}$

Yao, M., Wang, R., Zhao, Z., Liu, Y., Niu, Z., and Chen, J. (2018). A flexible all-inone lithium-sulfur battery a flexible all-in-one lithium-sulfur battery. Acs Nano 12, 12503-12511. doi: 10.1021/acsnano.8b06936

Yao, S., Cui, J., Huang, J.-Q., Lu, Z., Deng, Y., Chong, W. G., et al. (2018). Novel 2D Sb2S3 Nanosheet/CNT coupling layer for exceptional polysulfide recycling performance. Adv. Energy Mater. 8:1800710. doi: 10.1002/aenm.2018 00710

Yu, M., Yin, Z., Yan, G., Wang, Z., Guo, H., Li, G., et al. (2020). Synergy of interlayer expansion and capacitive contribution promoting sodium ion storage in S, N-Doped mesoporous carbon nanofiber. J. Power Sources 449:227514. doi: 10.1016/j.jpowsour.2019.227514

Yu, Q., Luo, R., Bai, X., Yang, W., Lu, Y., Hou, X., et al. (2018). Rational design of double-confined Mn2O3/S@Al2O3 nanocube cathodes for lithium-sulfur batteries. J. Solid State Electrochem. 22, 849-858. doi: 10.1007/s10008-0173818-6

Zhao, M.-Q., Liu, X.-F., Zhang, Q., Tian, G.-L., Huang, J.-Q., Zhu, W., et al. (2012). Graphene/Single-Walled Carbon Nanotube Hybrids: one-step catalytic growth and applications for high-rate Li-S batteries. ACS Nano 6, 10759-10769. doi: $10.1021 / \mathrm{nn} 304037 \mathrm{~d}$

Zhao, Q., Hao, X. G., Su, S. M., Ma, J. B., Hu, Y., Liu, Y., et al. (2019). Expandedgraphite embedded in lithium metal as dendrite-free anode of lithium metal batteries. J. Mater. Chem. A 7, 15871-15879. doi: 10.1039/c9ta04240g

Zhao, X., Chen, H., Kong, F., Zhang, Y., Wang, S., Liu, S., et al. (2019). Fabrication, characteristics and applications of carbon materials with different morphologies and porous structures produced from wood liquefaction: a review. Chem. Eng. J. 364, 226-243. doi: 10.1016/j.cej.2019.01.159

Zhao, Y., Wei, S., Wang, F., Xu, L., Liu, Y., Lin, J., et al. (2020). Hatted 1T/2H-Phase MoS2 on Ni3S2 Nanorods for Efficient Overall Water Splitting in Alkaline Media. Chem. A Eur. J. 26, 2034-2040. doi: 10.1002/chem.201904307

Zheng, M., Chi, Y., Hu, Q., Tang, H., Jiang, X., Zhang, L., et al. (2019). Carbon nanotube-based materials for lithium-sulfur batteries. J. Mater. Chem. A 7, 17204-17241.

Zhu, J., Yildirim, E., Aly, K., Shen, J., Chen, C., Lu, Y., et al. (2016). Hierarchical multi-component nanofiber separators for lithium polysulfide capture in lithium-sulfur batteries: an experimental and molecular modeling study. J. Mater. Chem. A 4, 13572-13581. doi: 10.1039/c6ta04577d

Zhu, W., Zhang, Z., Wei, J., Jing, Y., Guo, W., Xie, Z., et al. (2020). A synergistic modification of polypropylene separator toward stable lithium-sulfur battery. J. Membr. Sci. 597:117646. doi: 10.1016/j.memsci.2019.117646

Zou, K., Li, N., Dai, X., Jing, W., Shi, M., Lu, C., et al. (2020). Lightweight Freestanding CeF3 Nanorod/Carbon Nanotube Composite Interlayer for Lithium-Sulfur Batteries. ACS Appl. Nano Mater. 3, 5732-5742. doi: 10.1021/ acsanm.0c00920

Zou, P., Lin, Z., Fan, M., Wang, F., Liu, Y., and Xiong, X. (2020). Facile and efficient fabrication of Li3PO4-coated Ni-rich cathode for high-performance lithium-ion battery. Appl. Surf. Sci. 504:144506. doi: 10.1016/j.apsusc.2019. 144506

Zuo, X., Zhen, M., and Wang, C. (2019). Ni@N-doped graphene nanosheets and CNTs hybrids modified separator as efficient polysulfide barrier for highperformance lithium sulfur batteries. Nano Res. 12, 829-836. doi: 10.1007/ s12274-019-2298-7

Conflict of Interest: The authors declare that the research was conducted in the absence of any commercial or financial relationships that could be construed as a potential conflict of interest.

Copyright (c) 2020 Wei, Liu, Zhai, Wang, Ren, Tao, Li, Wang and Ren. This is an open-access article distributed under the terms of the Creative Commons Attribution License (CC BY). The use, distribution or reproduction in other forums is permitted, provided the original author(s) and the copyright owner(s) are credited and that the original publication in this journal is cited, in accordance with accepted academic practice. No use, distribution or reproduction is permitted which does not comply with these terms. 